University of Wollongong

Research Online

Faculty of Engineering and Information

Faculty of Engineering and Information

Sciences - Papers: Part A

Sciences

$1-1-2016$

\title{
Cloud computing adoption decision modelling for SMEs: a conjoint analysis
}

Salim Al Isma'ili

University of Wollongong, szaai787@uowmail.edu.au

Mengxiang Li

University of Wollongong, mli@uow.edu.au

Jun Shen

University of Wollongong, jshen@uow.edu.au

Qiang $\mathrm{He}$

Swinburne University of Technology, qhe@swin.edu.au

Follow this and additional works at: https://ro.uow.edu.au/eispapers

Part of the Engineering Commons, and the Science and Technology Studies Commons

Research Online is the open access institutional repository for the University of Wollongong. For further information contact the UOW Library: research-pubs@uow.edu.au 


\title{
Cloud computing adoption decision modelling for SMEs: a conjoint analysis
}

\begin{abstract}
Cloud computing is an emerging technology that promises competitive advantages, cost savings, enhanced business processes and services, and various other benefits to enterprises. Despite the rapid technological advancement, the adoption of cloud computing is still growing slowly among small and mediumsized enterprises (SMEs). This paper presents a model to support the decisionmaking process, using a multi-criteria decision method PAPRIKA for the socio-technical aspects influencing SMEs cloud adoption decision. Due to the multifaceted nature of the cloud computing adoption process, the evaluation of various cloud services and deployment models have become a major challenge. This paper presents a systematic approach to evaluating cloud computing services and deployment models. Subsequently, we have conducted conjoint analysis activities with five SMEs decision makers as part of the distribution process of this decision modelling based on predetermined criteria. With the help of the proposed model, cloud services and deployment models can be ranked and selected.
\end{abstract}

\section{Keywords}

smes, cloud, conjoint, computing, analysis, adoption, decision, modelling

Disciplines

Engineering | Science and Technology Studies

\section{Publication Details}

Al Isma'ili, S., Li, M., Shen, J. \& He, Q. (2016). Cloud computing adoption decision modelling for SMEs: a conjoint analysis. International Journal of Web and Grid Services, 12 (3), 296-327. 


\title{
Cloud computing adoption decision modelling for SMEs: A conjoint analysis
}

\author{
Salim Al-Isma'ili ${ }^{1}$, Mengxiang Li $^{2}$, Jun Shen ${ }^{2}$ \\ School of Computing and Information Technology \\ University of Wollongong, Wollongong, Australia. \\ Email: ${ }^{1}$ szaai787@uowmail.edu.au; ${ }^{2}\{$ mli,jshen $\} @$ uow.edu.au
}

\author{
Qiang He \\ School of Software and Electrical Engineering \\ Faculty of Science, Engineering \& Technology \\ Swinburne University of Technology, Australia \\ Email: qhe@swin.edu.au
}

\begin{abstract}
Cloud computing is an emerging technology that promises competitive advantages, significant cost savings, enhanced business processes and services, and various other benefits to enterprises. Despite the rapid technological advancement, the adoption of cloud computing is still growing slowly among small and medium-sized enterprises (SMEs). This paper presents a model to support the decision-making process, using a multi-criteria decision method PAPRIKA for the sociotechnical aspects that have an impact on SMEs cloud computing adoption process. Due to the multifaceted nature of the cloud computing adoption process, the evaluation and selection of various cloud services and deployment models have become a major challenge. This paper presents a systematic approach to evaluating cloud computing services and deployment models. Subsequently, we have conducted conjoint analysis activities with five SMEs decision makers as part of the distribution process of this decision modelling based on predetermined criteria. With the help of the proposed model, cloud services and deployment models can be ranked and selected based on their economic values, advantages, compatibility with in-house systems, integrability \& manageability, security \& privacy concerns, reliability, availability, features \& management. The adaptability and the feasibility of the proposed method in cloud computing adoption demonstrated with five real-world cases.
\end{abstract}

Keywords: Cloud Adoption, Cloud Services, Potentially All Pair-wise RanKings of all possible Alternatives (PAPRIKA), Small and Medium-sized Enterprises (SMEs).

Copyright @ 2016 Inderscience Enterprises Ltd. 
Biographical notes: Mr. Salim AI-Isma'ili is a Ph.D. student in the School of Computing and Information Technology, University of Wollongong (UOW). He received his Bachelor degree in Management in 2005 and his Master degree in Computer Science from the University of Wollongong in 2006. His research interests include cloud computing adoption, business information systems, and decision modelling.

Dr. Mengxiang Li is a Lecturer of School of Computing and Information Technology at UOW. He has had publishing success with leading information systems journals such as Journal of MIS, Decision Support Systems, Information \& Management and the International Journal of Electronic Commerce. His articles have also appeared in premium international conferences, such as International Conference on Information Systems (ICIS), European Conference on Information Systems (ECIS), Pacific Asia Conference on Information Systems (PACIS) and Australasian Conference on Information Systems (ACIS).

Dr. Jun Shen is an Associate Professor of School of Computing and Information Technology at UOW. His research interests include Services economies, bio-inspired algorithms, costeffective and energy-saving computing, services computing, cloud computing, SOC adoption in SMEs, and Big Data. He has had over 120 publications in the leading information systems journals and conferences. He is the principal supervisor of Salim.

Dr. Qiang He is a Lecturer of Department of Computer Science and Software Engineering at Swinburne University of Technology. He received his first Ph.D. degree in information and communication technology from Swinburne University of Technology, Australia, in 2009 and his second Ph.D. degree in computer science and engineering from Huazhong University of Science and Technology (HUST), China, in 2010. He is now a lecturer at Swinburne University of Technology. His research interests include software engineering, cloud computing, and services computing.

This paper is a revised and expanded version of a paper entitled 'Cloud Computing Adoption Decision Modelling for SMEs: From the PAPRIKA Perspective' presented at The 4th International Conference on Frontier Computing (FC 2015), Bangkok, Thailand, 9-11 September 2015.

\section{Introduction}

SMEs (Small and Medium-sized Enterprises) sector is one of the major business entities that significantly benefit from cloud computing services (Dillon and Vossen, 2014, Carcary et al., 2014b). With the rapid growth of the cloud computing service market, there is a broad range of available cloud services with similar functions in the mundane market. Practitioners in SMEs are facing a tough decision on the selection of cloud computing service for their business activities. It is because the adoption decision shifts from measuring the fit between cloud computing service and the SMEs' business activity to a comprehensive analysis of all potential factors that can influence the cloud computing service adoption and utilisation. Example of those influential factors are benefit-driven perspective (e.g., improved efficiency, 
increased availability, fast deployment, and elastic scalability) (Oracle, 2010), risk-driven perspective (e.g., security concern, privacy issues, and information loss) (Wu et al., 2013, Daniel et al., 2014, Dutta et al., 2013). Thus, the adoption of cloud computing services in SMEs is a complex decision-making process, which requires the consideration of multi-criteria decision-making.

Australian SMEs are the main contributors to the Australian economy (ABS, 2013). Cloud computing can leverage the economic growth of this sector with the existence of the necessary factors such as stable market condition, trusted regulations, and experience manpower (McKinnar and Kathage, 2014). The advent of cloud computing could provide SMEs with the opportunity to explore new market and provide efficient customer services. The technology can help in reducing the drawbacks of the traditional IT investments regarding high-cost requirements for systems procurement, implementation, and experimentation. Although there have been an increasing number of studies in recent years toward investigating cloud computing adoption in SMEs (El-Gazzar, 2014, Oliveira et al., 2014, Hsu et al., 2014, Carcary et al., 2014a), a review of the related literature indicates that there is a dearth of studies of multi-criteria decision-making approaches for the adoption of cloud computing services in SMEs (Yang and Tate, 2012). Two issues arise for SMEs when plan to make cloud adoption decisions: (1) What options of cloud solutions are available to these SMEs? And what variables will become determinants for them to make adoption decisions? (2) What are the decision criteria associated with these alternatives determine the most suitable choice for their particular requirement?

To fill this gap, this paper presents a multi-criteria cloud computing service adoption decision model for SMEs and validates this decision model by anchoring on the method of Potentially All Pair-wise RanKings of all possible Alternatives (PAPRIKA). To evaluate the proposed model, we designed a conjoint analysis distribution activity (preference survey), which was distributed electronically to several decision makers in Australian SMEs. Our findings show a hierarchical ranking of the importance of different factors that SMEs are concerned about for cloud computing service adoption. The advantages offered by cloud computing services are the top most, followed by the economic values gained from cloud services. The third important attribute is the cloud services reliability and availability. Cloud services features and management is ranked fourth. Control ability (integrability and manageability) is listed fifth. The sixth identified prioritised attribute is the compatibility of cloud services with the legacy systems. Security and privacy issues are the least ranked determinants for SMEs in their decision for the adoption of cloud services. The alternatives: cloud services and its deployment models, were achieved and ranked in sequence as followings: Private IaaS, Private PaaS, Private SaaS, Hybrid IaaS, Hybrid PaaS, Hybrid SaaS, Public IaaS-System, Public PaaS, Public SaaS, Public IaaS-Storage, Legacy IT (not to adopt).

The following section describes the related work in cloud computing adoption field and the PAPRIKA method. In Section 3 the cloud computing service adoption decision model is described. Section 4 shows the method of validating the multi-criteria decision model. The results of conjoint analysis and the discussion of our findings are then presented in Section 5. Section 6 shows the study limitations and opportunity for improvement of the model. Finally, Section 7 concludes the paper. 


\section{Literature review}

This section begins with an introduction to the basic concepts and related work. Then it discusses the SMEs briefly. After that it presents the cloud computing deployment and service models. Later it discusses briefly cloud computing adoption decision of SMEs. Various methods used in ranking frameworks are then discussed. The section concludes with an overview of the PAPRIKA scoring method and with the justifications of its applicability.

\subsection{Background}

All around the world, SMEs play a vital role in the economic development of countries (Abor and Quartey, 2010). SMEs perceived as sources of earnings, employment opportunities creation, social prosperity, regional developments, and exportation of products. OECD (2006) reported that SMEs constitute the largest percentage of the private sector in the world. Therefore, it is evident that technological innovation can equip SMEs with the necessary capabilities to enhance the global economy. Technology has significantly influenced various aspects of life and changed the way how business is conducted. Remarkably, SMEs are not away from this innovation wave, and it is trending gradually towards the adoption of ICT (Houghton and Winklhofer, 2004). Cloud computing is the technology of the century, and it has high expectations to solve the business challenges that are faced by SMEs (RioBelver et al., 2012).

In Australia, the SMEs are the skeleton of the country economy (ACMA, 2014). For facilitating changes in any industry, three crucial components need to be considered: processes, people, technology (Chen and Popovich, 2003). Continues business processes are the key to success and it is an ongoing effort to improve the quality of products, services, or processes. The cloud computing services are promoted by providers in offering efficient, robust, and modern information systems requirements to businesses. These technological solutions are promising to provide scalable, elastic, and costeffective solutions delivered over the Internet on pay-as-you-go pricing model. These services are available to any business and it can be useful for SMEs to consider due to their limited technical capabilities requirements regarding investment, as well as planning, and risk assessments of acquiring the right technological products and solutions for their needs.

In another side, security is one of the highly addressed negative issues in the adoption process; fortunately, the economy of scale allows computer service providers (CSPs) to provide better security measures to their clients at lower cost. Furthermore, cloud services could be the solution for enterprises which are lack in financial capabilities for acquiring in-house ICT solutions (Hancock and Hutley, 2012). These services, in turn, can lead to an increase in the growth of the small organisation through accessing advanced IT solutions that maybe in the past were far away from their budget. Furthermore, less requirement of upfront capital investment which is replaced by on-going subscription for cloud products is allowing smaller organisations to enter and compete in new markets. This flexibility in investment can eventually increase productivity and innovation. The diffusion of cloud computing created a considerable contribution to the growth estimated at a rate of (between $0.05 \%$ to $0.3 \%$ ) and created around one million new employment opportunities in Europe (Hancock and Hutley, 2012). From a different angle, (Pike_research, 2010) reported that implementing cloud solutions could reduce up to $30 \%$ of the associated carbon footprint per user for large organisations and about $90 \%$ for smaller 
businesses.

\subsection{Small and medium enterprises}

The unique characteristics of small businesses demand developing different models of investigation than the ones used in large businesses contexts. In most cases, large businesses face many of the same constraints and these effects can be more significant on small businesses. Resources such as skills, time, and employees are not the major issues in large businesses, while they can create significant disadvantages in small businesses (Cohn and Lindberg, 1972). Therefore, organisational theories and practises that apply to a large business not necessarily will be suitable for small business context (Cohn and Lindberg, 1972, Welsh and White, 1981, Dandridge, 1979).There is a need to investigate cloud computing adoption in small businesses separately rather than in a generic form.

SMEs contribute positively to performance and competitiveness of nations' economies (Bridge and O'Neill, 2012). Moreover, their structural characteristics give them the flexibility to change easily and explore new fields in responding to the demanding market trends and economic situations (Storey and Cressy, 1996). However, despite this, they have little influence on economic and government decision makers and are more influenced by macroeconomics effects (Curran and Blackburn, 2000). Technically, small companies are more flexible in innovation and quicker respond to market changes. However, their main disadvantages are their lower capacity in gaining the benefits of economies of scale in resource intensive projects. Financial capabilities is another negative issue they face, and usually, a small change in the business activities can lead to costly or even catastrophic results (Bridge and O'Neill, 2012). Hence, in many cases, SMEs chooses low-cost technological resources to cater for their needs (Saini et al., 2012). Cloud computing could be one of the potential technological resources that can be considered by this sector by taking into account the various deployment models and services offered as it will be discussed in the next two sections.

As the market states, cloud computing could be a tool for providing elastic and efficient business models (Chang et al., 2010). This statement suggests that organisations can grasp the benefits offered by cloud computing easily. However, in practice, the indicators showed that there was a slow adoption of cloud computing services (Khajeh-Husseini et al., 2010). Security issues are one of the main hindrances to the adoption of this technology (Kim et al., 2009). Security is not only a concern fo large organisations but it is also a concern for all organisation types and sizes including SMEs (Kim et al., 2009). SMEs have many sensitive data that they need to protect including quotations to their customers, financial details, company databases, trade secret, email accounts, research findings, confidential research, and feasibility studies (Misra and Mondal, 2011). A study conducted by Catteddu and Hogben (2009) found that the main obstacles to cloud computing adoption are unwillingness for capital expenditure, privacy, security risks, availability and integrity of service and data, and data confidentiality. Data sensitivity is also a barrier for SMEs in the adoption of cloud services (Jain and Bhardwaj, 2010, Misra and Mondal, 2011). A study by Koehler et al. (2010) revealed that in addition to security; reliability is also one of the main obstacles to cloud computing adoption.

For SMEs in particular, the cloud can play a vital role in reducing the gap and increase competition with larger enterprises through reducing the capital constraints and lack of technical knowledge (Michael et al., 2013). On the 
other hands, studies indicated that the growth of cloud computing is not as it is expected (Jelonek and Wysłocka, 2014, GoGrid, 2012, Yeboah-Boateng and Essandoh, 2014, Mohlameane and Ruxwana, 2014). The same situation also persists in Australian SMEs market and the adoption rate found to be slower in SMEs comparing to large firms (Minifie, 2014)

\subsection{Cloud Computing Deployment Models}

Cloud computing has been defined by the US National Institute of Standards and Technology (NIST) as: “... a model for enabling ubiquitous, convenient, on-demand network access to a shared pool of configurable computing resources (e.g. networks, servers, storage, applications, and services) that can be rapidly provisioned and released with minimal management effort or service provider interaction" (Mell and Grance, 2011, p.2). Technically, cloud computing has been categorised into four deployment models: private, public, community, and hybrid (Mell and Grance, 2011).

Private cloud - is exclusively used by the single organisation, management can be internally or by a third party, and hosting can be inhouse or externally (NIST, 2014). This infrastructure is capital intensive, however, more secure (CloudAndCompute.com, 2014).

Public Cloud - In this infrastructure, the services are rendered over the network to the public, and it is offered as free or on a tenancy-pricing model (Subashini and Kavitha, 2011). Security was one of the main concerns when the services are offered over a non-trusted network (Schneiderman, 2011). The cloud is managed by a third party service provider (examples include Amazon EC2 and Goggle Apps) (Armbrust et al., 2010).

Community cloud - shared cloud platform for common business-oriented organisations. The management of the cloud can be either internally or externally, and the cost is spread among the users help in establishing mutual benefits and cost savings (Mell and Grance, 2011)

Hybrid cloud - is when a single organisation adopts two or more clouds(private, community or public)and grasp the benefits offered by multiple cloud resources (Mell and Grance, 2011)

\subsection{Cloud Computing Service Models}

Cloud computing has three services models:

Software-as-as-Service (SaaS) - access to application software and databases via web services provided by services providers on renting basis rather than installing them on user's premises (an example of services includes Sales force.com and Goggle Apps). It uses two concepts of ondemand software and pay-per-use basis (Tsai et al., 2010).

Platform-as-a-service (PaaS) - a platform with all required computing resources including programming languages, database, and web server provided by service providers to software developers. This platform reduces the cost complexity requirement for software development and management of the underlying hardware and software capabilities (an example of these include are Microsoft Azure and Google App Engine) (Boniface et al., 2010).

Infrastructure-as-a-service (IaaS) Renting access physical computing resources or usually virtual machines, data centres, and other resources over a network. The services are scalable through a large number of virtual machines based on users requirements (Amies et al., 2012). 


\subsection{Cloud computing adoption decision of SMEs}

Our investigation of the relevant literature indicated that there are limited studies available regarding the cloud computing service adoption decision making. There are also few studies that proposed viable frameworks (or models) for assisting in the determination of ranking and selection process from the perspective of SMEs.

Han et al. (2009) proposed an automated system for cloud selection based on tangible and easily measurable parameters such as Quality of Service (QoS) and Virtual Machine (VM) performance, based on SaaS category. The study, however, did not take into consideration other relevant variables in the context. As an alternative approach, $\mathrm{Li}$ et al. (2010) proposed an evaluation tool based on IaaS and PaaS services such as storage, network, and processing performance as selection criteria for different cloud computing services providers. Our review of the relevant literature indicates that PAPRIKA was used only once in the context of cloud computing for modelling resource scheduling in a simulation study conducted by (Lawrance and Silas, 2013). Our study will be the first to apply the PAPRIKA method in modelling cloud computing adoption decision in the context of real-world cases of SMEs.

Multi-Criteria Decision Making (MCDM) techniques have been considered by other researchers like Godse and Mulik (2009), using Analytical Hierarchy Process (AHP). It provided a wider dimension for studying various subjective criteria but was limited to the analysis of SaaS services. Rehman et al. (2011) further developed a more complex model, the limited technical capabilities of SMEs made it less practical for use in their case. The approach proposed within the present study addresses these limitations and offers a model that is capable of analysing some cloud services and deployment models. The model contains distribution activities for ranking, prioritising, selecting, and valuing, which are easy to implement and straightforward to use by the decision makers.

\subsection{PAPRIKA method for cloud computing adoption decision-making}

Choosing the most appropriate cloud computing deployment model and selecting suitable cloud services for businesses is not an easy task. The reason behind this is that there are many technological solutions provided by cloud computing services providers and also various direct and indirect factors that influence this decision and need to be considered carefully for expert judgment. In this regard, PAPRIKA is a method for establishing decision-makers' preferences through using pair-wise rankings of alternatives (Hansen and Ombler, 2008).

In PAPRIKA method, the underlying mechanism compares two criteria at a time that offers more accurate results in opposing to other pair-wise comparison systems. This approach is a useful tool for subjective and incomplete information and, therefore, it can produce practical solutions for real world use. The method involves prioritizing ranking of competing alternatives through evaluating all possible undominated pairs of attributes, presenting the final results in a useful model (Hansen and Ombler, 2008). More specifically, PAPRIKA method uses only two criteria selection, whereas SMART/SWING (Simple Multi-Attribute Rating Technique using Swing weights), outranking, and some CA (Conjoint Analysis) methods use ranking, direct rating, weighting to rank alternatives. In these methods, scoring the criteria is based on individuals, experts, and public opinion. Rating the criteria and alternatives by decision makers can introduce confusion in data interpretation. This is becoming obvious of the different 
interpretation of the rating scale by various people in a specific research focused group. Hence, Forman and Selly (2001) stated that the scoring of alternatives depends on decision maker's opinion and understanding of the scoring scale.

PAPRIKA method is appropriate for analysing the cloud computing service adoption for SMEs with two reasons. First, this method arguably was selected as it closer to the human logic of choice, simple, and at the same time have the complexity feature of analysing different criteria and attributes including qualitative and quantitative data types. PAPRIKA helped in modelling real-world cases in various complex and dynamic fields (Ombler and Hansen, 2012). One of the powerful features of PAPRIKA is in its ability in surveying any number of criteria and levels; as these numbers increase, the number of potential alternatives (combinations) increases exponentially. These capabilities and features are useful for investigating the multifaceted nature of decision-making process of SMEs and the dynamics of cloud computing technology. For example, six criteria and four levels create 4096 possible alternatives (Hansen and Ombler, 2008). The PAPRIKA method largely reduces the number of selection the decisionmaker have to make by reducing 'dominant' pair-wise comparisons and use the transitivity feature to respond implicitly to other questions. Domination occurs when a decision is not required for certain alternatives due to the high rate of some alternatives in comparison with others. Then, the 'undominated' pairs are to be analysed by the software. The 'undominated' pair occurs when one alternative has, at least, one criterion with a higher rate and a least one criterion with a lower rate in comparison with other alternatives. The software eliminates all the redundant choices when comparing two 'undominated' pairs via transitivity. For example, if choice A is ranked higher than choice B and choice B is higher than choice C, then by transitivity, choice A is ranked higher than choice C. After the two choices, the third choice becomes redundant. Then the software progress in selecting another choice and the process continues until all 'undominated' pairs processed and ranked.

Second, PAPRIKA provides more preference comparison than most other scoring methods (Hansen and Ombler, 2008), such as Adaptive Conjoint Analysis (ACA), Discrete Choice Experiments/Conjoint Analysis (DCE/CA) and the Analytical Hierarchy Process (AHP) (Saaty, 1990). Appendix-A illustrates the comparison between various scoring methods used in the decision-making process. PAPRIKA is a useful tool for designing a decision model for such that of cloud services where there are a number of solutions, and those solutions keep in growing, coming with its additional challenges which also influence SMEs decision makers from various socialtechnical perspectives.

Furthermore, Sullivan (2012) discussed in his study about three methods that elicit preference in-formation in ordinal form namely: PAPRIKA, ACA, and DCE/CA. In ACA and DCE/CA methods, however, usually, two or more choice sets are presented which can include more than two criteria for each choice set (Ryan and Gerard, 2003). The more the number of criteria, the more complex the choice becomes. Additionally, focusing on some criteria and eliminating the other for the purpose of simplification can lead to inaccuracy in estimating criteria weights (Cameron and DeShazo, 2010). On the other hands, PAPRIKA method offers a larger number of choices for decision-makers for a value model in comparing with other methods (Hansen and Ombler, 2008). For example, DCE/CA offers a smaller number of choices sets in corresponding with the number of scenarios presented (Raghavarao et al., 2010). The smaller number of choice sets presented by 
this method can be good regarding reducing the effort that takes decisionmakers for attempting to the preferences; however, it can cause unreliability issues in the results. ACA method also presents limited scenarios to the decision-makers that can make the preferences process of various choices sets inefficient.

Additionally, The AHP method presents the decision-makers with the framework of making pair-wise comparisons at each hierarchal level for the presented criteria or alternatives. It has been argued that selecting preference based on methods other than cardinal form generates consistency and reliable results (Moshkovich et al., 2002). PAPRIKA method can compare criteria weights of one decision-maker with another in the trading-off the same criteria basis. However, AHP method can do the same only if decisionmakers have used the same attributes and/or levels (Bolloju, 2001). The aggregation of weight in this approach depends on setup agreed by decisionmakers, if it is to combine their judgments, then a geometric mean is used. Additionally, 'experts' can combine their results and geometric mean is also used and it is further can be used to rank the 'experts' themselves (Saaty, 2008).

In summary, deciding on the appropriate cloud computing deployment and service option is a difficult process. Various factors need to be considered in the decision-making context and sometimes the decision could involve various people. There are different approaches for ranking, some of which have been discussed in this paper. In this research, we contend that PAPRIKA is an appropriate method for analysing the multi-criteria decisionmaking of cloud computing service adoption among SMEs.

\section{$3 \quad$ Modelling the Cloud Adoption Process}

This section discusses the process of establishment of the relevant criteria and levels. The criteria, levels, and the alternative solutions are then presented.

\subsection{Model design}

The development of a decision model for cloud adoption decision-making process was implemented based on researchers' previous three studies (Alismaili et al., 2015b, Al-Isma'ili et al., 2016a, Al-Isma'ili et al., 2016b): (1) Literature review (2) 15 semi-structured interview which included 4 cloud computing services providers, 4 SMEs cloud computing adopters, 4 prospectors, and 3 non-cloud computing adopters (3) 203 stratified survey studies among SMEs in different sectors across Australia. The target population in the qualitative and quantitative studies were SMEs decision makers in the adoption of new technologies. The insights obtained from all those sources of studies have been the feed or the building blocks in constructing the decision model for cloud computing. Some of the attributes have been modified, and some have been discarded to fit in the context of PAPRIKA methodology because the way of developing the criteria and their descriptive levels (Figure1) is different from the quantitative study. For example, with this methodology, it is not possible to use Likert scale measurement because decision modelling is different. Furthermore, the wording and design of the decision model will follow a different system. Figure 1 explains this meaning. This research is a trial in providing organisations with a framework to assist them in making their decision process more informative and easier. The model was then experimented and tested by five SMEs decision makers to ensure that it is functioning properly 
and if there are any opportunities for improvement to be considered for the future. In our earlier study, an initial model was simulated with two different scenarios (one scenario was more concern about security and privacy issues, and the other one was more concern about the advantages offered by cloud services over the security concerns) and found to match the predefined criteria with their associated alternatives that proofed that the model was functioning properly (Alismaili et al., 2015a)This motivated us to experiment the tuned model with real-world cases.

Designing a decision model requires first identifying the goals or alternatives or the necessary solutions for the decision maker to rank and select among them. Then, specifying the criteria (attributes) and its level of importance to the alternatives. Table 1 below illustrates the relevant influential factors (attributes) that have been found in our previous work.

Table1 Conceptual attributes of the decision model

\begin{tabular}{|l|l|}
\hline Attributes & Definitions from cloud computing perspective \\
\hline $\begin{array}{l}\text { Economic } \\
\text { value }\end{array}$ & $\begin{array}{l}\text { The extent to which cloud computing is perceived to be } \\
\text { economically viable to use. }\end{array}$ \\
\hline Compatibility & $\begin{array}{l}\text { The degree to which cloud computing is viewed as consistent } \\
\text { with the existing values, past experience, and needs of potential } \\
\text { users. }\end{array}$ \\
\hline $\begin{array}{l}\text { Integrability } \\
\text { \& } \\
\text { manageability }\end{array}$ & $\begin{array}{l}\text { The degree to which cloud computing is perceived as integrable } \\
\text { and manageable }\end{array}$ \\
\hline $\begin{array}{l}\text { Security \& } \\
\text { privacy }\end{array}$ & $\begin{array}{l}\text { The perceived security and privacy concerns of cloud computing } \\
\text { concern due to the occurrence of data loss. }\end{array}$ \\
\hline $\begin{array}{l}\text { Reliability \& } \\
\text { availability }\end{array}$ & $\begin{array}{l}\text { The extent of users perceived reliability and availability of cloud } \\
\text { computing services }\end{array}$ \\
\hline $\begin{array}{l}\text { Features \& } \\
\text { management }\end{array}$ & $\begin{array}{l}\text { The perceived features \& management of cloud computing } \\
\text { services }\end{array}$ \\
\hline $\begin{array}{l}\text { Adoption } \\
\text { decision }\end{array}$ & Investigated status of cloud computing services adoption decision \\
\hline
\end{tabular}

The following table explains the alternatives cloud computing deployment models and services. This was adopted from (Saripalli and Pingali, 2011) study.

Table2 Alternative solutions. Adopted from (Saripalli and Pingali, 2011).

\begin{tabular}{|l|l|}
\hline Alternatives (goals) & Explanation \\
\hline Public IaaS: System & VM images hosted on IaaS public cloud \\
\hline Public IaaS: Storage & Storage cloud by a public vendor \\
\hline Public PaaS & Platform to build apps and workflows \\
\hline Public SaaS & Application hosting on a public platform \\
\hline Private IaaS & VMs and storage hosted on private cloud \\
\hline Private PaaS & Dev platforms on demand on a private cloud. \\
\hline Private SaaS & Applications hosted on a private cloud \\
\hline Hybrid IaaS & $\begin{array}{l}\text { Part of the VMs or storage hosted on public IaaS, rest is on } \\
\text { premise private. }\end{array}$ \\
\hline Hybrid PaaS & $\begin{array}{l}\text { Part of the workflow hosted on public PaaS, while the rest is } \\
\text { on-premise private. }\end{array}$ \\
\hline Hybrid SaaS & $\begin{array}{l}\text { Part of a distributed app hosted on public SaaS, while the rest } \\
\text { is on-premise private. }\end{array}$ \\
\hline
\end{tabular}


Figure 1 demonstrates the study constructed decision model with its various setup levels starting from left to right.

Figure1 Constructed decision model
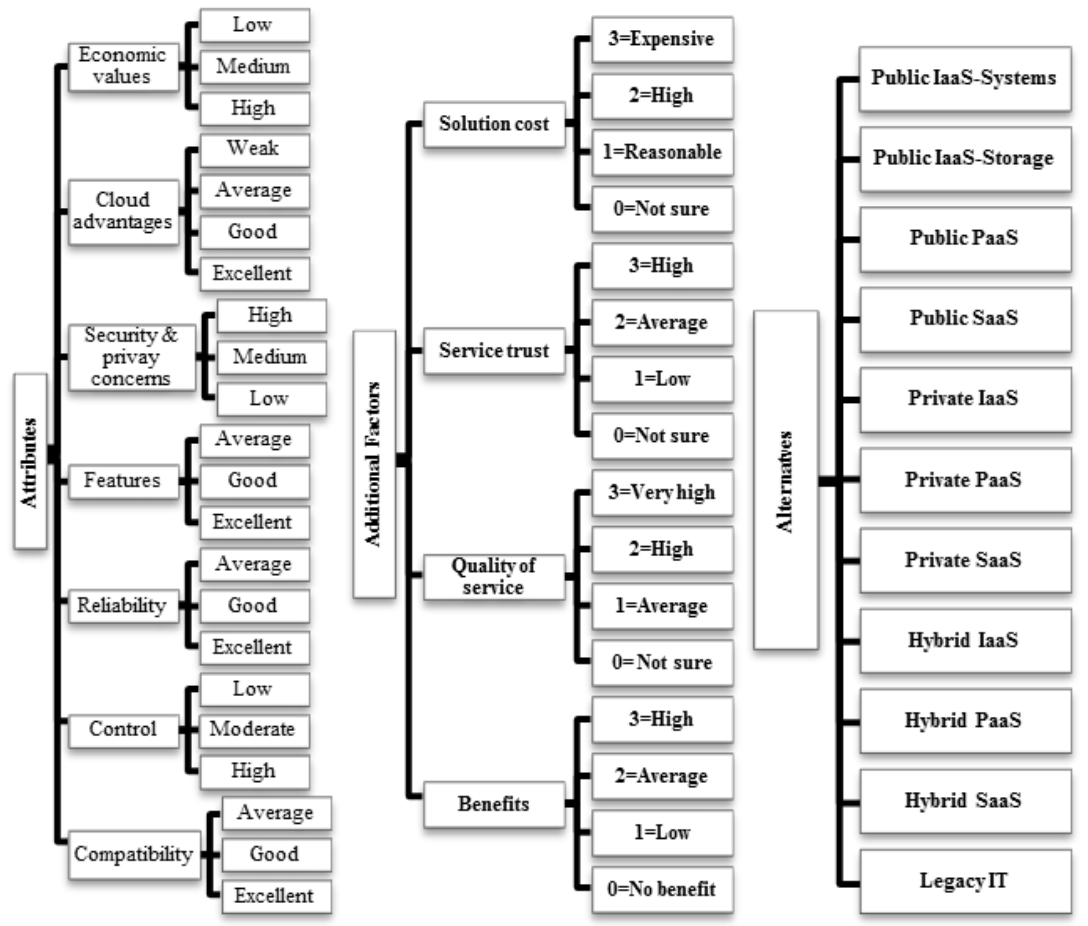

This model design took into consideration achieving selection of alternative goals based on considering additional factors such as solution cost and service trust, and with a provision of a budget constraint control if required to be input by the user. The attributes level ranking starts from top (lowest ranked) to down (highest ranked). For example, for cloud advantages attribute, the excellent level has the highest rank and weak level has the lowest rank.

This section described the process of eliciting the relevant criteria for use in the preference survey. The next section will discuss the methodology used to conduct this research.

\section{Research Method}

Decision-making is the process that most of the time involves selecting the optimal solution among a set of possible alternatives. The choice decision in uncertainty and risk situation usually involves scoring and ranking of alternatives. For this paper, PAPRIKA approach was used to design and develop a decision modelling framework (Hansen and Ombler, 2008). Using PAPRIKA methodology requires having two main components: criteria and alternatives. Modelling the cloud adoption decision-making process will be implemented by using two methods: 1 . Literature review 2 . A collection of expert opinion by designing appropriate survey. By this way, a set of criteria will be identified within the context of this research which the determinants factors in the adoption of cloud computing services. These criteria create the foundation of the value model for a set of alternatives that need to be ranked in corresponding with each criterion. 
The PAPRIKA method uses pair-wise preferences evaluation based on trade-off process through selection one of the three options: 1- pair one is better than pair two; 2-pair two is better than pair one; 3- both pairs are equal (Fig. 2). The value model or the preference values are represented by the relative importance 'weight' of the criteria that is calculated via mathematical methods (i.e. linear programming). The relative importance of each criterion is obtained from its highest ranked category, and the total of all the highest categories in each criterion is equal to $100 \%$. Cost-benefits calculations are another useful measure that can be considered in alternatives scoring through Pareto analysis that provides an additional "value for money" evaluation tool for final selection of alternatives. PAPRIKA pointing system allows the use of criteria which can be either of quantitative nature (e.g. number of employees and experience) or qualitative nature (technological factors, organisational factors, and environmental factors) in the adoption of cloud computing). Non-categorical criteria can also be represented with different as appropriate to the case study (e.g. low rank, medium rank, and high rank).

Figure2 Example of a pair-wise-ranking trade-off question for scoring the value model presented in graphical user interface.

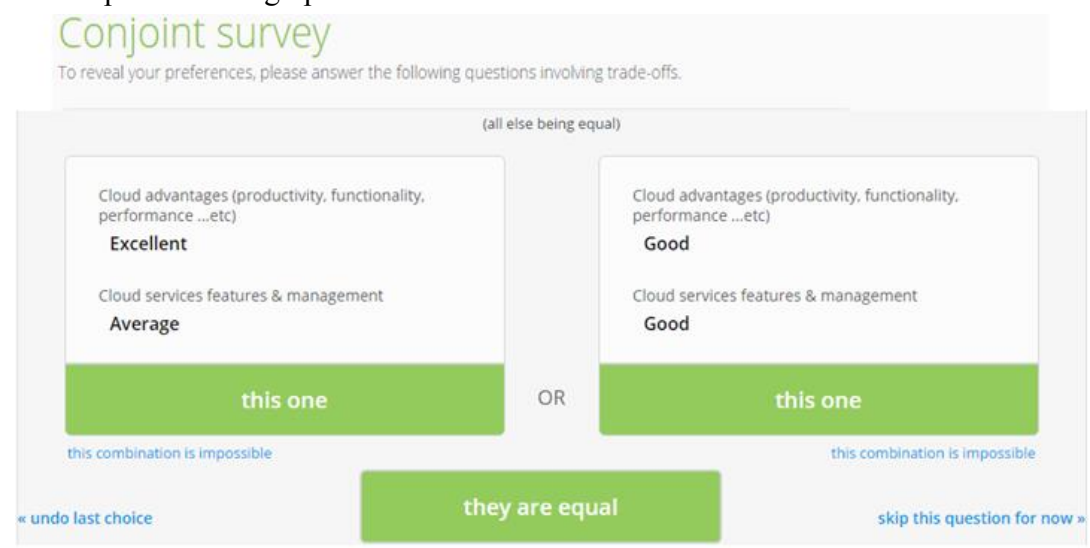

PAPRIKA uses 'pair-wise ranking' method for ranking of alternatives. This approach is in contrast with most other decision facilitator methods which use 'scaling' or 'ratio' measurements for ranking of preferences. For example, AHP is relying on a scaling method which is based on 1 to 9 points and evaluating which of the two defined criteria are more important in this scale system. With PAPRIKA method, users are allowed to choose one alternative between just two, which is easier and natural as in the human life daily decision. PAPRIKA can process any number of pair-wise rankings of the hypothetical alternatives required by decision makers. Therefore, PAPRIKA method presents better confidence in decision-making. Below is "The Cloud Computing Choice Model Process".

1. Setup: identifying the concepts and the activity mode. The activity mode for this decision model is "Part-worth utilities"- and it is about discovering the participant's representation of the relative importance (weights) of the attributes.

2. Attributes: developing the relevant criteria for the concepts with its associated level of options.

3. Concepts: they are the alternatives or the available cloud computing options to the SMEs.

4. Choices, Part-worth utilities, and Ranked options: at this stage, the administrator conducts testing of the model before distributing it for 
activities.

5. Decision: this is a conjoint survey mode. It involves the distribution process of the survey with the means of emails and sing-up web page. Participants make their decisions based on trading-off between two attributes each time. The outcome of this step is the presentation of the participant's representation of the relative importance (weights) of the criteria to them (completed preference values).

6. Ranked concepts: presentation of the ranked concepts including all the attributes and the other specified concepts as a complete decision model

7. Selection: choosing among the presented concepts with an option to specify a budgeting constraint based on requirement.

This paper used PAPRIKA scoring method through its running environment 1000Minds software and not other methods for the following reasons: (1) User friendly (2) Less complex as pair-wise comparison is defined by two criteria (3) Less complex as pair-wise comparison is defined by two criteria (4) Generates individual weights for every decision-maker which can be easily combined (5) Decision survey designed is clear, direct, and costeffective (6) The survey format is robust, clear, and easy to follow. 1000Minds is the only software that supports PAPRIKA method (Ombler and Hansen, 2012).

\subsection{Survey}

The online survey for this paper was constructed using 1000Minds software (Ombler and Hansen, 2012). Then it was distributed via the same platform to several SMEs for the purpose of testing the applicability of our designed model.

Respondents were asked to choose which of two hypothetical criteria on cloud computing (figure 2) they prefer. They had the option to select 'they are equal' and 'skip this question for now'. Respondents can finish the survey once they start or resume at any time if they break by following the personal invitation link, which they have received in their email. Respondents also have the opportunity to undo their answers and re-answer. The software updates the responses automatically for on-time analysis. Using this method of surveying is cost-effective due to its minimal administration costs in comparison with the traditional mode of offline face-to-face surveying.

Regarding the reliability of the process, we did test by ourselves before disseminating it to the participants. The results were matching the expectations based on the identified criteria and their matching alternatives. However, there was one issue identified in the way respondents make their decisions. For example, Respondents may have selected any of the options without a careful reading of the question, just to finish the questionnaire faster. This issue shared between all other forms of surveys, particularly the long and complex one, which might lead to participant's loss of interest (De Vaus, 2013). In our methodology, this issue was not significant, because respondents attended to only two criteria at a time (the task is less complicated) and the average number of questions respondents have to take was 30 .

\subsection{Respondents}

The companies contact details were obtained from an online database namely "FindTheCompany" (FindTheCompany, 2016). With search criteria, in this database, for businesses that have 0-200 employees, private, from 
different industries, and across Australia result came out with 312,725 SMEs. The survey was distributed randomly to forty organisations, which were selected randomly from this database, among them five only finished the complete survey. Table 3 presents the participant progress in the survey activity. The aim of this paper is to evaluate the applicability of the method and the developed model. Therefore, the number of collected cases is sufficient for this purpose, and a large number of respondents will not make any difference in this context. The developed model can be used in the future for detailed analysis of a larger scale population. At this stage, the model serves as a proof of concept for our proposal of decision-making model and not a detailed quantitative analysis.

Table3 Participants progress

\begin{tabular}{|l|l|}
\hline Progress & Participants \\
\hline Excluded from activity & 0 \\
\hline Email not sent yet (or no address) & 0 \\
\hline Email sent, not started yet & 40 \\
\hline Started (not finished yet) & 3 \\
\hline Finished & 5 \\
\hline
\end{tabular}

Table 4 below presents the five participant's details.

Table4 The five participant's details

\begin{tabular}{|l|l|l|l|l|l|}
\hline $\begin{array}{l}\text { Participant } \\
\text { ID }\end{array}$ & Gender & Role & $\begin{array}{l}\text { Business } \\
\text { type }\end{array}$ & $\begin{array}{l}\text { Employee } \\
\text { number }\end{array}$ & $\begin{array}{l}\text { Adopted } \\
\text { services }\end{array}$ \\
\hline 141109 & Male & Director & IT & 13 & $\begin{array}{l}\text { Webmail \& } \\
\text { storage }\end{array}$ \\
\hline 141057 & Male & CEO & Finance & 7 & $\begin{array}{l}\text { Webmail \& } \\
\text { application }\end{array}$ \\
\hline 140957 & Male & Managing & Retail & 21 & webmail \\
\hline 140943 & Male & Director & Services & 8 & webmail \\
\hline 140958 & Male & Company & Business & 16 & Webmail \& \\
& & Manager & services & & CRM \\
\hline
\end{tabular}

\section{$4.3 \quad$ Cloud computing services \& deployments choice modelling}

This model used conjoint analysis activity that was distributed to five SMEs from different business activities. Organisations revealed their utility values, represented the relative importance (weights) of conjoint attributes for the decision model. A model is a tool for Conjoint Analysis also known Discrete Choice Experiment and for Multi-Criteria Decision-Making (MCDM).

Practically, the developed model supports three activities: (1) Discovering decision-makers' part-worth utilities (2) Ranking concepts (3) Selecting concepts. Ranking and selecting concepts are not in the scope of this paper. The original model ranking was established by the researchers own intuition that is mainly originated from the qualitative and qualitative studies that have been conducted by the researcher and also from the insights of the previous literature.

\section{Relevant definitions of some terminologies:}


Concepts: the alternatives that consist of a group of levels (e.g. Public Cloud IaaS, Private Cloud PaaS).

Part-worth utilities: values that indicate the relative importance (weights) of the attributes.

\subsection{Choice model activity steps}

For discovering SMEs part-worth utility values (will be achieved via decision

makers answering questions which involve trade-offs between the attributes), the following main steps have been carried out:

Step 1: Attributes

Development of the attributes and its relevant ranking levels with the possibilities of re-order of attributes and re-rank of levels.

Step2: Concepts (alternatives)

This activity involves entering the combinations that have been considered for each cloud computing services and deployment model type (e.g. Private IaaS, Hybrid PaaS).

Step3: Choice, part-worth utilities, and ranked choices

SMEs decision makers were asked a sequence of simple questions based on selecting between two hypothetical concepts (cloud computing services) presented on two attributes per question and involving a trade-off. As a result, 'part-worth utilities' of the attributes are generated. They indicate the relative importance (weights) of the attributes. Lastly, based on the decision maker's part-worth utilities and the way concepts have been rated, the decision model ranks the concepts from highest to lowest according to their 'total utilities' (scores out of 100).

\subsection{Distributed process}

The decision-making process was created through inviting various SMEs decision makers' participants randomly to undertake an online preference survey (conjoint analysis) which is embedded in the model itself to reveal their individual preferences. The results can be visualised individually for each participant and also for a group of participants. The model has survey managing tools such as electronic distribution of surveys by emails, checking participant's progress, and sending reminders.

\section{$5 \quad$ Results \& Discussion}

This section will report the results of the preferences that have been established by the five companies that have completed the survey. As it has been mentioned earlier, the concepts have been ranked according to the researcher's previous studies, literature review, and their initiative knowledge. This activity can be handled by the model with real-world cases of SMEs if needed. However, the activity was not considered a direct application and within the scope of this study. The main activity of consideration of this paper is the conjoint analysis. The report classifies the results as followings:

\subsection{Part-worth utilities and attributes rankings}

Utility values symbolize the relative importance (weights) of the attributes 15 
presented by the attribute rankings (Table 6). Each attribute's weight relates to the \% value for its highest level (bolded, Table 5) - and the radar chart (Fig.3) visualise the attributes weight. These bolded values - weights - sum to $100 \%$ (i.e. 1 ).

\section{Explanation of utility values}

In fulfilling the ethical consideration, the conjoint analysis survey activity was anonymous. For this reason, all participants were identified by a unique ID number generated by the model. For a given participant (ID No.141109), the value of the highest-ranked level (i.e. bolded, table3) for each attribute indicates that attribute's importance relative to the other attributes (for that particular participant). For instance, if the highest level of attribute "economic value" is worth $8.5 \%$ and the highest level for attribute "cloud advantages" is worth $45.4 \%$, then the later attribute is more important than the former attribute for about $36.9 \%$. From these values it can also be stated that the "economic value" attribute importance to the participant is $8.5 \%$ and"cloud advantages" attribute is $45.4 \%$.

Nevertheless, it is perfectly correct that the relative importance of an attribute will highly be based on the extensiveness of the identified level for the attributes. Precisely, the comprehensive and more relevant the levels, the more appropriate will be the attribute to the decision activity.

Besides, the attribute utility value between the lowest and highest levels represents both the attribute's relative importance and the levels' performances in relation to the highest level. This is the reason why 'middle' values are smaller than the bolded values. Median and mean values and rankings are calculated for participants on average as a group. Standard Deviation 'SD' (applying the ' $n$ ' method generated on all participant values).

The additional visualisation charts and tables provided in this section are some of the tools that are generated by the model which can help decision maker in having a clearer picture of the situation and make a more informative decision.

The radar chart and other tables and charts in this section are usefully visualised tools for understanding the utility values in Table 5. Table 5 presents the ranking of the attributes. Participants ranking of each attribute are also presented. Mean and median values and rankings are the established average for the group.

Table 7 illustrates each attributes weight corresponds to the $\%$ value for its highest level (illustrate in Table. 5). It represents the marginal rate of substitution of the column attributes for the row attributes. For instance, (row 1, col7: 17.4) shows that cloud advantages were more important to participants for 17.4 than the security and privacy issues and (row 7, col1: 0.1 ) shows that security and privacy issues constitute only 0.1 of importance to the cloud advantages.

Table5 Utility values (Preference values)

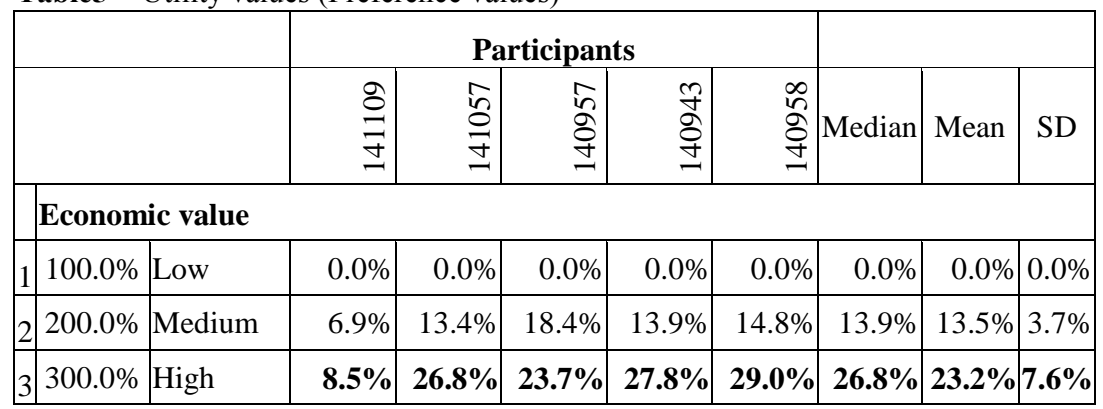


Table5 Continued

\begin{tabular}{|c|c|c|c|c|c|c|c|c|c|c|}
\hline & & & \multicolumn{5}{|c|}{ Participants } & \multirow[b]{2}{*}{ Median } & \multirow[b]{2}{*}{ Mean } & \multirow[b]{2}{*}{ SD } \\
\hline & & & $\begin{array}{l}8 \\
\varrho \\
\exists \\
\end{array}$ & \begin{tabular}{l}
$\hat{n}$ \\
0 \\
\multirow{z}{\pm}{}
\end{tabular} & ñ & $\begin{array}{l}\text { fa } \\
\text { oे } \\
\text { I } \\
\end{array}$ & 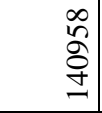 & & & \\
\hline \multicolumn{11}{|c|}{ Cloud advantages (productivity, functionality, performance ..., etc) } \\
\hline 1 & $100.0 \%$ & Weak & $0.0 \%$ & $0.0 \%$ & $0.0 \%$ & $0.0 \%$ & $0.0 \%$ & $0.0 \%$ & $0.0 \%$ & $0.0 \%$ \\
\hline 2 & $200.0 \%$ & Average & $16.2 \%$ & $13.0 \%$ & $18.4 \%$ & $14.2 \%$ & $14.2 \%$ & $14.2 \%$ & $15.2 \%$ & $1.9 \%$ \\
\hline 3 & $300.0 \%$ & Good & $32.3 \%$ & $26.0 \%$ & $21.1 \%$ & $28.1 \%$ & $16.9 \%$ & $26.0 \%$ & $24.9 \%$ & $5.4 \%$ \\
\hline 4 & $400.0 \%$ & Excellent & $45.4 \%$ & $39.0 \%$ & $30.9 \%$ & $42.3 \%$ & $25.7 \%$ & $39.0 \%$ & $36.7 \%$ & $7.3 \%$ \\
\hline \multicolumn{11}{|c|}{ Security \& Privacy concerns } \\
\hline 1 & $100.0 \%$ & High & $0.0 \%$ & $0.0 \%$ & $0.0 \%$ & $0.0 \%$ & $0.0 \%$ & $0.0 \%$ & $0.0 \%$ & $0.0 \%$ \\
\hline 2 & $200.0 \%$ & Medium & $4.6 \%$ & $0.4 \%$ & $0.7 \%$ & $0.9 \%$ & $0.5 \%$ & $0.7 \%$ & $1.4 \%$ & $1.6 \%$ \\
\hline 3 & $300.0 \%$ & Low & $6.2 \%$ & $0.8 \%$ & $1.3 \%$ & $1.1 \%$ & $1.1 \%$ & $1.1 \%$ & $2.1 \%$ & $2.0 \%$ \\
\hline \multicolumn{11}{|c|}{ Cloud services feature \& management } \\
\hline 1 & $100.0 \%$ & Average & $0.0 \%$ & $0.0 \%$ & $0.0 \%$ & $0.0 \%$ & $0.0 \%$ & $0.0 \%$ & $0.0 \%$ & $0.0 \%$ \\
\hline 2 & $200.0 \%$ & Good & $7.7 \%$ & $2.8 \%$ & $6.6 \%$ & $5.4 \%$ & $2.7 \%$ & $5.4 \%$ & $5.0 \%$ & $2.0 \%$ \\
\hline 3 & $300.0 \%$ & Excellent & $12.3 \%$ & $5.7 \%$ & $8.6 \%$ & $13.6 \%$ & $8.2 \%$ & $8.6 \%$ & $9.7 \%$ & $2.9 \%$ \\
\hline \multicolumn{11}{|c|}{ Cloud services reliability and availability } \\
\hline 1 & $100.0 \%$ & Average & $0.0 \%$ & $0.0 \%$ & $0.0 \%$ & $0.0 \%$ & $0.0 \%$ & $0.0 \%$ & $0.0 \%$ & $0.0 \%$ \\
\hline 2 & $200.0 \%$ & Good & $13.8 \%$ & $6.5 \%$ & $4.6 \%$ & $5.4 \%$ & $2.7 \%$ & $5.4 \%$ & $6.6 \%$ & $3.8 \%$ \\
\hline 3 & $300.0 \%$ & Excellent & $15.4 \%$ & $12.6 \%$ & $9.2 \%$ & $8.0 \%$ & $13.7 \%$ & $12.6 \%$ & $11.8 \%$ & $2.8 \%$ \\
\hline \multicolumn{11}{|c|}{ Control (Integrability \& Manageability) } \\
\hline 1 & $100.0 \% \mathrm{I}$ & Low & $0.0 \%$ & $0.0 \%$ & $0.0 \%$ & $0.0 \%$ & $0.0 \%$ & $0.0 \%$ & $0.0 \%$ & $0.0 \%$ \\
\hline 2 & $200.0 \%$ & Moderate & $4.6 \%$ & $1.2 \%$ & $10.5 \%$ & $2.8 \%$ & $9.8 \%$ & $4.6 \%$ & $5.8 \%$ & $3.7 \%$ \\
\hline 3 & $300.0 \%$ & High & $8.5 \%$ & $2.4 \%$ & $17.8 \%$ & $5.1 \%$ & $12.0 \%$ & $8.5 \%$ & $9.2 \%$ & $5.4 \%$ \\
\hline \multicolumn{11}{|c|}{ Compatibility with in-house hardware \& software } \\
\hline 1 & $100.0 \%$ & Average & $0.0 \%$ & $0.0 \%$ & $0.0 \%$ & $0.0 \%$ & $0.0 \%$ & $0.0 \%$ & $0.0 \%$ & $0.0 \%$ \\
\hline 2 & $200.0 \%$ & Good & $3.1 \%$ & $6.5 \%$ & $2.6 \%$ & $1.4 \%$ & $4.9 \%$ & $3.1 \%$ & $3.7 \%$ & $1.8 \%$ \\
\hline 3 & $300.0 \%$ & Excellent & $3.8 \%$ & $12.6 \%$ & $8.6 \%$ & $2.0 \%$ & $10.4 \%$ & $8.6 \%$ & $7.5 \%$ & $4.0 \%$ \\
\hline
\end{tabular}

The ranked attributes with all the mean and median ranks for all the participants, are listed in Table 6 and presented graphically in Figure 3 and 4.

Table6 Attribute rankings

\begin{tabular}{|c|c|c|c|c|c|c|c|}
\hline & $\begin{array}{l}8 \\
0 \\
\\
\end{array}$ & $\begin{array}{l}n \\
0 \\
\Xi \\
\end{array}$ & $\mid \begin{array}{l}n \\
n \\
o \\
y \\
\end{array}$ & 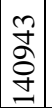 & $\begin{array}{l}\infty \\
2 \\
2 \\
o \\
⿱ \\
1\end{array}$ & Median* & Mean** \\
\hline $\begin{array}{l}\text { Cloud advantages } \\
\text { (productivity, functionality, performance ...etc.) }\end{array}$ & 1.0 & 1.0 & 1.0 & 1.0 & 2.0 & 1.0 & 1.2 \\
\hline Economic value & 4.5 & 2.0 & 2.0 & 2.0 & 1.0 & 2.0 & 2.3 \\
\hline Cloud services reliability and availability & 2.0 & 3.5 & 4.0 & 4.0 & 3.0 & 3.5 & 3.3 \\
\hline Cloud services features \& management & 3.0 & 5.0 & 5.5 & 3.0 & 6.0 & 5.0 & 4.5 \\
\hline
\end{tabular}


Table6 Continued

\begin{tabular}{|c|c|c|c|c|c|c|c|}
\hline & 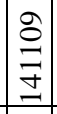 & $\begin{array}{l}n \\
n \\
\ddots \\
\pm \\
-1\end{array}$ & $\begin{array}{l}\hat{n} \\
2 \\
\text { d } \\
\end{array}$ & 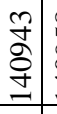 & \begin{tabular}{l}
$\infty$ \\
2 \\
2 \\
\multirow{2}{d}{} \\
\end{tabular} & Median* & Mean** \\
\hline Control (Integrability \& Manageability) & 4.5 & 6.0 & 3.05 & 5.04 & 4.0 & 4.5 & 4.5 \\
\hline Compatibility with in-house hardware \& software & 7.0 & 3.5 & 5.56 & 6.05 & 5.0 & 5.5 & 5.4 \\
\hline Security \& Privacy concerns & 6.0 & 7.0 & 7.07 & 7.07 & 7.0 & 7.0 & 6.8 \\
\hline
\end{tabular}

*The median value of each attribute is calculated by arranging the ranks for the attribute from lowest to highest and choosing the middle value.

**The mean rank is the average rank and is calculated by adding all the ranks for that particular attribute and dividing by the total number of participants (i.e. five).

The radar chart (Fig.3) illustrates the attributes weights; each coloured line in the chart represents the participant's preference on the attributes. The thicker black line in the radar chart below represents the mean value. Each one of the coloured lines represents an attribute with the same colour coding as presented in Fig 4. It can be observed from the chart (Fig.3) that cloud advantages received the highest mean weight $36.7 \%$ while security and privacy concerns had the lowest mean weight $2.1 \%$, which indicates the degree of significance of these attributes through the collective decisionmaking process that was established by the five decision-makers. The model can be used for individual or collective decision-making process. It depends on the design of the model and the objective that is intended to be achieved in the decision-making process.

Figure3 Radar chart of attribute weights

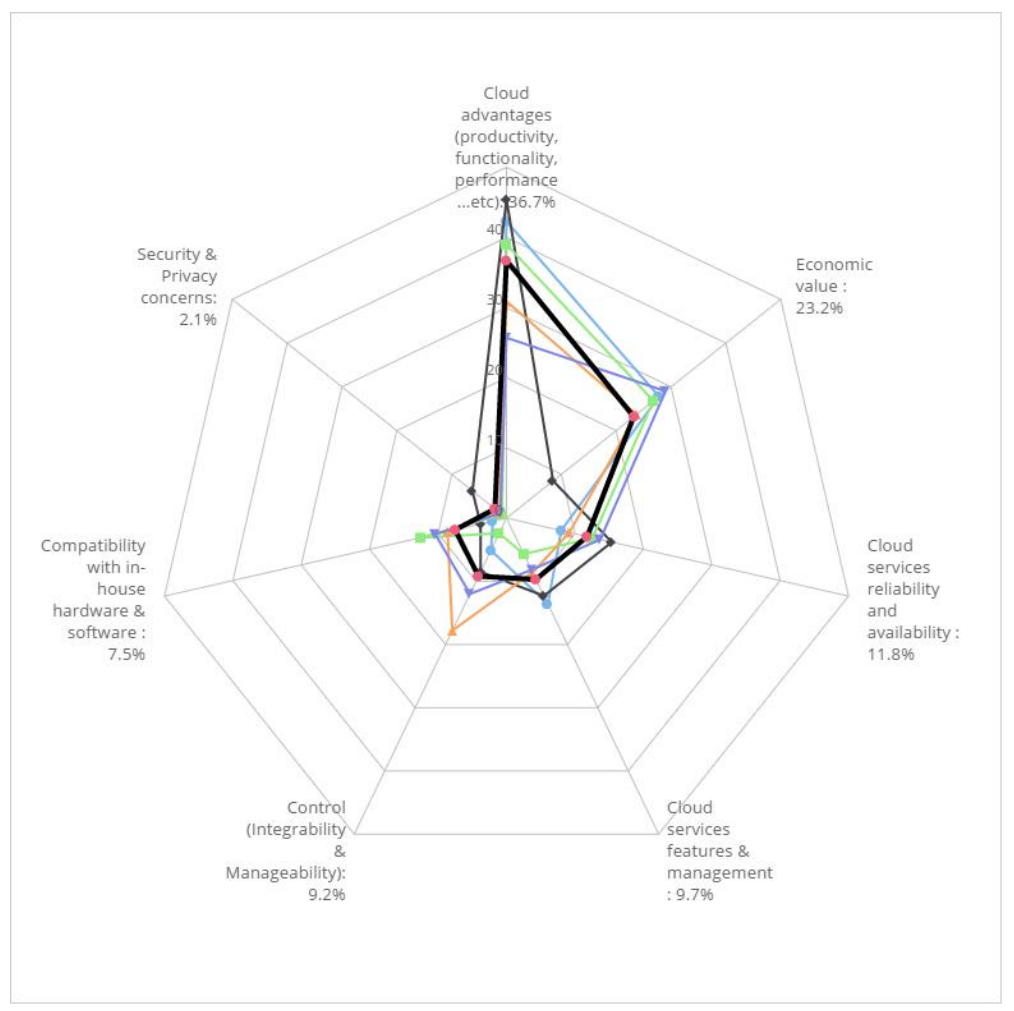


Table7 Relative importance of attributes (mean weights)

\begin{tabular}{|c|c|c|c|c|c|c|c|}
\hline & 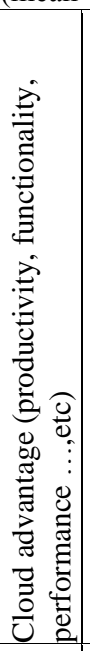 & 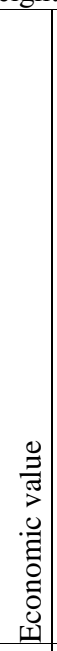 & 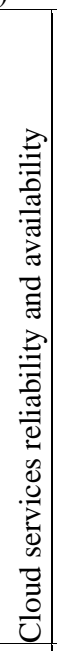 & 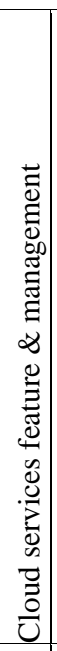 & 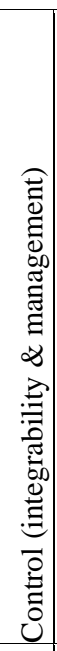 & 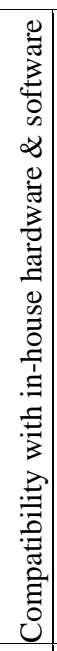 & 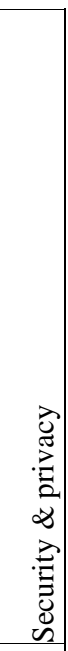 \\
\hline $\begin{array}{l}\text { Cloud advantages (productivity, } \\
\text { functionality, performance ..., etc) }\end{array}$ & & 1.6 & 3.1 & 3.8 & 4.0 & 4.9 & 17.4 \\
\hline Economic value & 0.6 & & 2.0 & 2.4 & 2.5 & 3.1 & 11.0 \\
\hline Cloud services reliability and availability & 0.3 & 0.5 & & 1.2 & 1.3 & 1.6 & 5.6 \\
\hline Cloud services features \& management & 0.3 & 0.4 & 0.8 & & 1.1 & 1.3 & 4.6 \\
\hline Control (Integrability \& Manageability) & 0.2 & 0.4 & 0.8 & 0.9 & & 1.2 & 4.4 \\
\hline $\begin{array}{l}\text { Compatibility with in-house hardware \& } \\
\text { software }\end{array}$ & 0.2 & 0.3 & 0.6 & 0.8 & 0.8 & & 3.6 \\
\hline Security \& Privacy concerns & 0.1 & 0.1 & 0.2 & 0.2 & 0.2 & 0.3 & \\
\hline
\end{tabular}

Figure4 Attribute value functions (mean utility values)

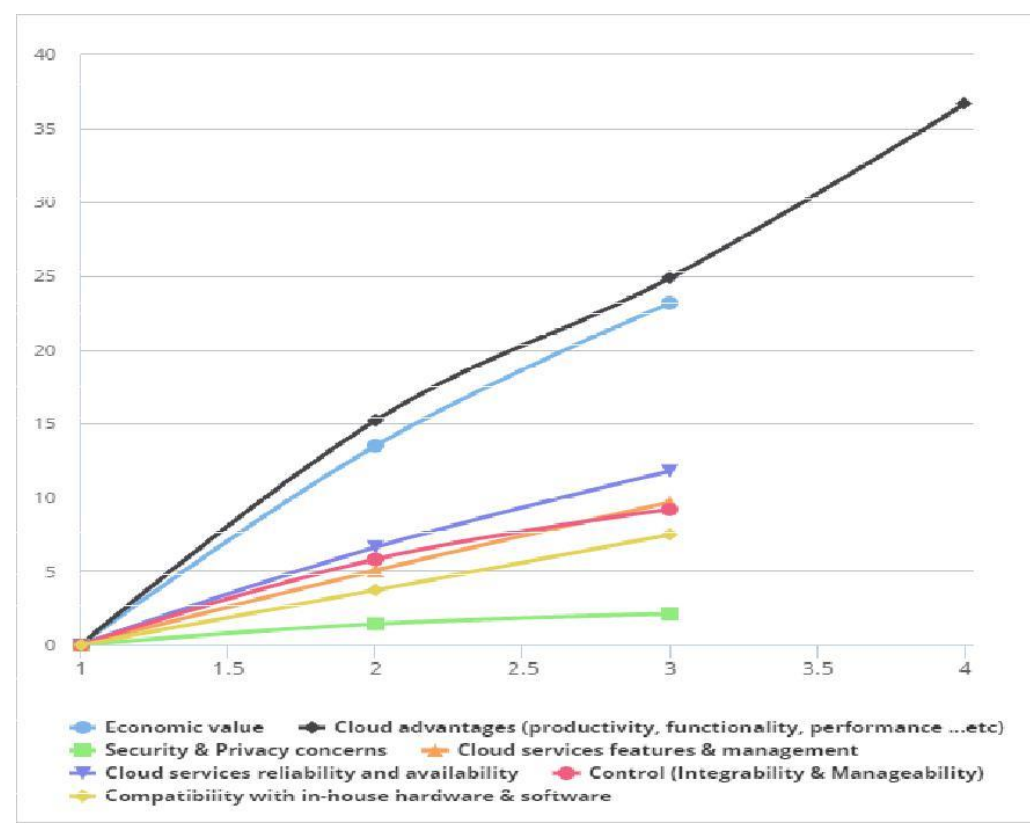

The advantages that are provided by cloud computing services such as functionality and performance have been considered the highest value based on the preference ranking of the participants. Whereas, security and privacy 
found to be the least concerned elements in the decision of the adoption of cloud computing services (Fig. 4 and Table 6).

Table8 Normalized criterion weights and single criterion scores (means)

\begin{tabular}{|c|c|c|c|}
\hline Attributes & Attribute weight & Level & Single attribute \\
\hline & (sum to 1) & & score $(0-100)$ \\
\hline \multirow{3}{*}{ Economic value } & \multirow{3}{*}{0.232} & Low & 0.0 \\
\hline & & Medium & 58.2 \\
\hline & & High & 100.0 \\
\hline \multirow{4}{*}{$\begin{array}{l}\text { Cloud advantages (productivity, } \\
\text { functionality, performance ...etc.) }\end{array}$} & \multirow{4}{*}{0.367} & Weak & 0.0 \\
\hline & & Average & 41.4 \\
\hline & & Good & 67.9 \\
\hline & & Excellent & 100.0 \\
\hline \multirow{3}{*}{ Security \& Privacy concerns } & \multirow{3}{*}{0.021} & High & 0.0 \\
\hline & & Medium & 67.3 \\
\hline & & Low & 100.0 \\
\hline \multirow{3}{*}{$\begin{array}{l}\text { Cloud services features \& } \\
\text { management }\end{array}$} & \multirow{3}{*}{0.097} & Average & 0.0 \\
\hline & & Good & 52.2 \\
\hline & & Excellent & 100.0 \\
\hline \multirow{3}{*}{$\begin{array}{l}\text { Cloud services reliability and } \\
\text { availability }\end{array}$} & \multirow{3}{*}{0.118} & Average & 0.0 \\
\hline & & Good & 56.3 \\
\hline & & Excellent & 100.0 \\
\hline \multirow{3}{*}{$\begin{array}{l}\text { Control (Integrability \& } \\
\text { Manageability) }\end{array}$} & \multirow{3}{*}{0.092} & Low & 0.0 \\
\hline & & Moderate & 63.4 \\
\hline & & High & 100.0 \\
\hline \multirow{3}{*}{$\begin{array}{l}\text { Compatibility with in-house } \\
\text { hardware \& software }\end{array}$} & \multirow{3}{*}{0.075} & Average & 0.0 \\
\hline & & Good & 49.6 \\
\hline & & Excellent & 100.0 \\
\hline
\end{tabular}

Table 8 provides a representation of the utility values showed in Table 2 . These values - weights - sum to $100 \%$ (i.e. 1). The values present each attributes importance relative to the other attribute and their significance to the participants. It is evident that 'cloud advantages' with a value of 0.367 has the highest level of relevance among other attributes. Table 7 illustrates the relative importance of attributes to each other in cross relationships by 
mean weights. Figure 4 shows a visualised picture of the attributes mean value functions that demonstrate the importance of cloud services productivity and functionality features over other attributes. Security and privacy were the least important factors in the consideration of the participants in their decision process for the adoption of cloud services.

\subsection{Ranking of concepts}

The tables and figures in this section present the results of the rankings of the entered concepts (alternatives) for the 5 participants on their group decision scenario on their selection of the cloud computing services and deployment models activity.

Fig. 5 shows the rankings of the 11 concepts ordered and normalized by mean rank. The colored lines represent the concepts, and the middle blue line represents the mean values. Each alternative is determined based on the criteria taking into account the preferences of the decision makers and the measurement scale. Each criterion is evaluated with a coefficient of importance (weight).

Participant's preferences decisions are illustrated in Table 6 from the most suitable options (concepts) to the least suitable option (concepts) based on their inputs in the preference survey.

Figure 5 Participants rankings of the 11 alternatives

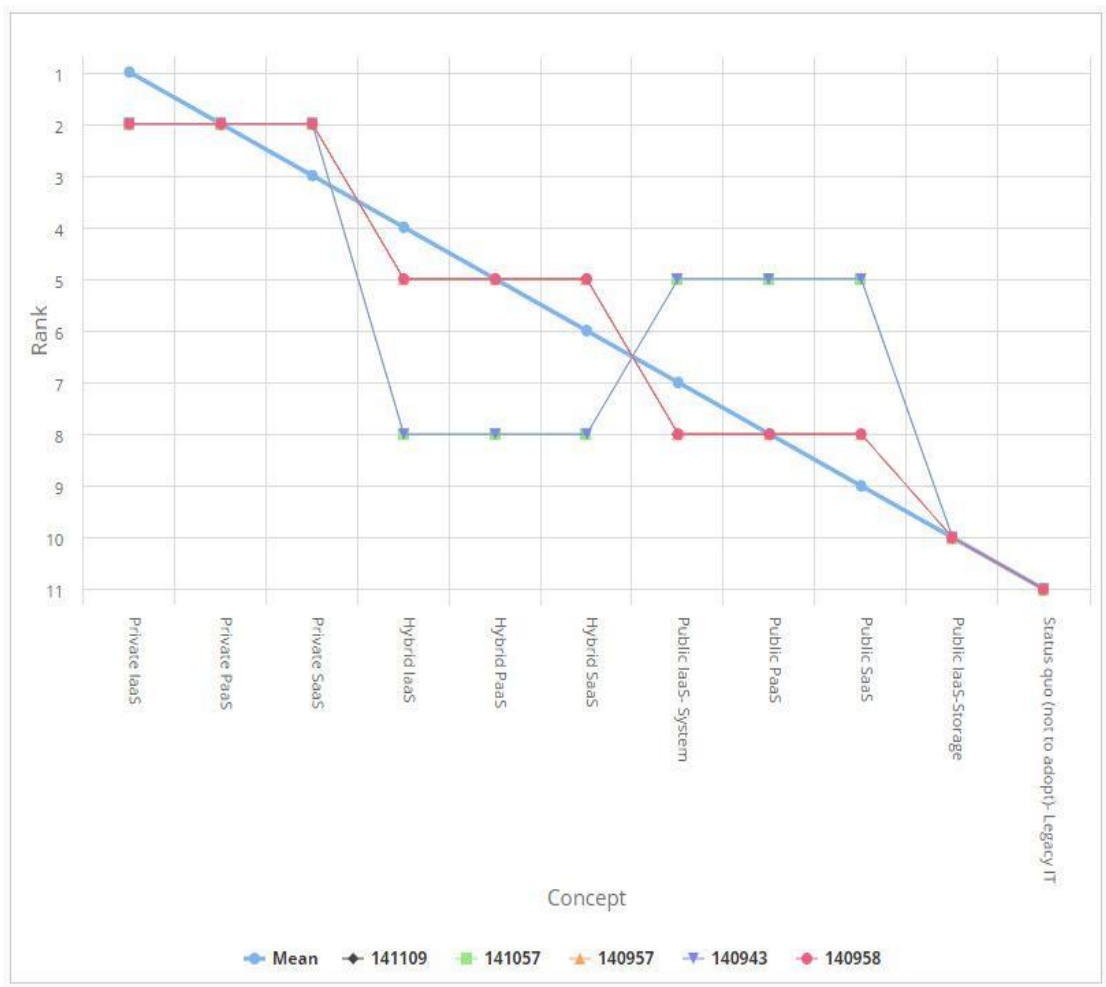

Table 9 shows the spearman's rank correlation coefficient (rs) results. This tool calculates the extent of similarity of 2 rankings of concepts and ranges between 1 and -1 . Three of the participants have a (rs) with mean value $=1$ which make their rankings identical. The other two participants (ID 141057 and ID 140943) with a (rs) value $=0.740$ for each of them have a greater degree to an identical as the value is close to number 1 . The total (rs) with a 
mean value of all the participants $=1$. In other words, the participants have an agreement with each other to a relatively large extent.

Table9 Rankings (mid-ranks) of the 11 concepts

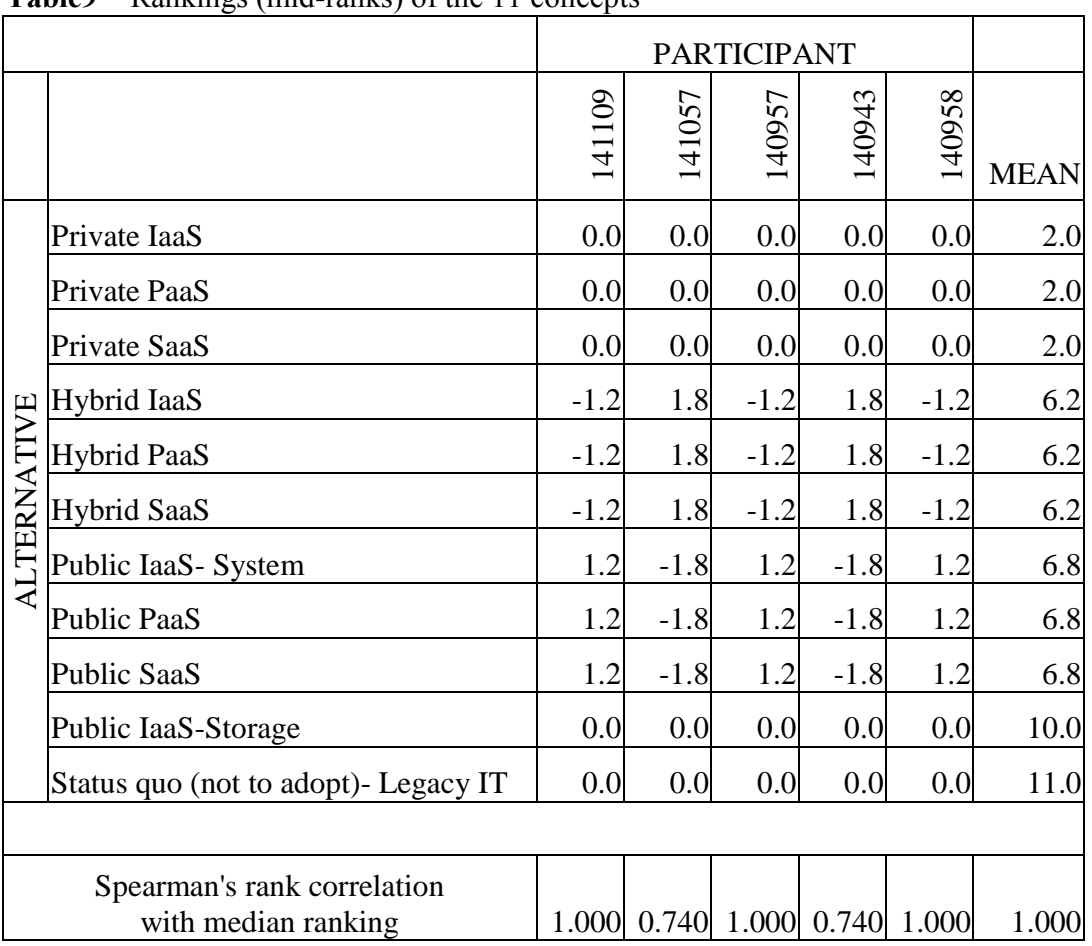

\subsection{Decision model}

Table 10 presents the final complete decision model achieved by the five participants who completed $100 \%$ the preference survey. It demonstrates the ranked alternatives in order of importance to the participants based on their judgment on a number of relevant criteria and the model also contain further factors that thought to be important to SMEs in their decision towards the adoption of cloud computing services. These factors are solution costs, services trust, quality of services, and benefits. Even though those specific factors were additional to the model and they were not included in the experiment with the participants, but they were linked with the model and were ranked intuitively by the researchers based on their previous qualitative, quantitative, and also on other literature.

\subsection{Selection (value for money model)}

The data in Table10 can be used to prioritise the cloud computing alternatives. For instance, the alternatives can be ranked according to their total score or according to 'other factors' such as solution cost, or service trust could be ranked based on a combination of factors. Value for Money chart (Fig. 6) provides decision-makers with an easy interface that contains all the variables required to select and prioritise the cloud computing alternatives (Golan and Hansen, 2008).The (x) axis in the chart (Fig.6) is represented by the solution cost for this case, and it can be represented by any other "additional factors" mentioned earlier and presented in Table10. 
Table10 The achieved decision model (Ranked concepts)

\begin{tabular}{|c|c|c|c|c|c|c|c|c|c|c|c|c|c|c|}
\hline \multirow[b]{2}{*}{ ALTERNATIVES } & \multicolumn{7}{|c|}{ CRITERIA } & \multirow[b]{2}{*}{ 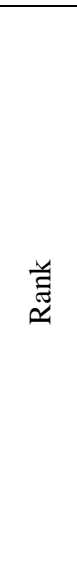 } & \multirow[b]{2}{*}{ 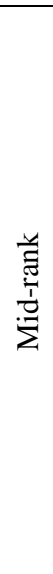 } & \multirow[b]{2}{*}{ 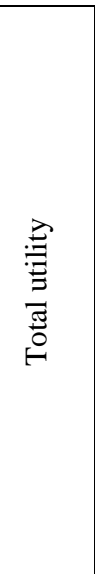 } & \multicolumn{4}{|c|}{ OTHER FACTORS } \\
\hline & 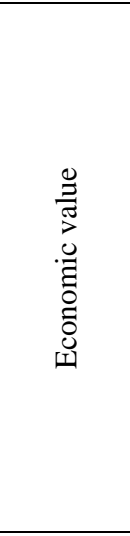 & 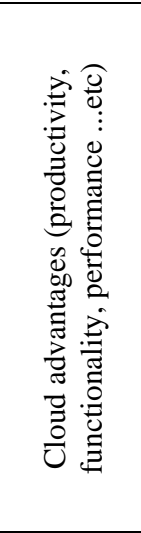 & 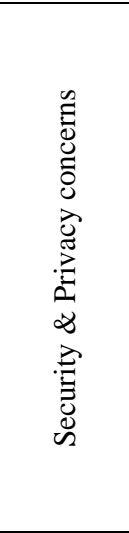 & 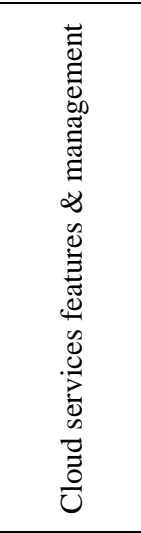 & 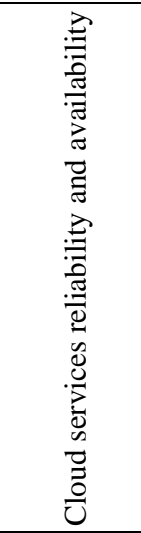 & 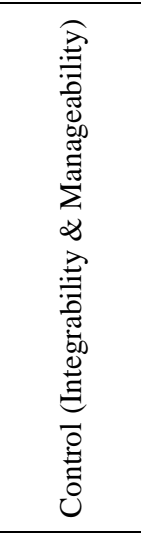 & 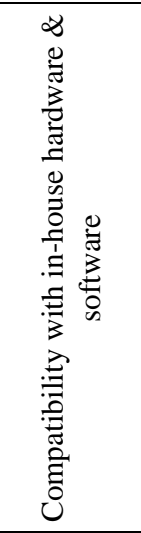 & & & & 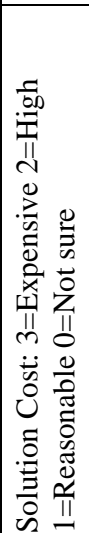 & 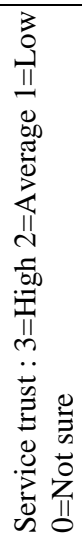 & 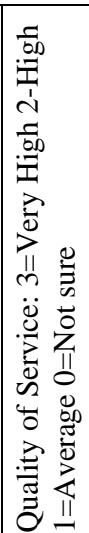 & 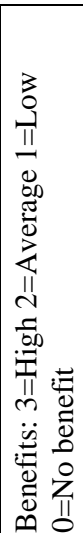 \\
\hline Private IaaS & High & Excellent & High & Excellent & Excellent & High & Excellent & $1 \mathrm{st}=$ & 2 & $88.5 \%$ & 3 & 3 & 3 & 3 \\
\hline Private PaaS & High & Excellent & High & Excellent & Excellent & High & Excellent & $1 \mathrm{st}=$ & 2 & $88.5 \%$ & 3 & 3 & 3 & 3 \\
\hline Private SaaS & High & Excellent & High & Excellent & Excellent & High & Excellent & $1 \mathrm{st}=$ & 2 & $88.5 \%$ & 3 & 3 & 3 & 3 \\
\hline Hybrid IaaS & Medium & Good & Medium & Good & Good & Moderate & Good & $4 \mathrm{th}=$ & 5 & $71.4 \%$ & 2 & 2 & 2 & 2 \\
\hline Hybrid PaaS & Medium & Good & Medium & Good & Good & Moderate & Good & $4 \mathrm{th}=$ & 5 & $71.4 \%$ & 2 & 2 & 2 & 2 \\
\hline Hybrid SaaS & Medium & Good & Medium & Good & Good & Moderate & Good & $4 \mathrm{th}=$ & 5 & $71.4 \%$ & 2 & 2 & 2 & 2 \\
\hline Public IaaS- System & High & Good & Low & Average & Average & Low & Good & $7 \mathrm{th}=$ & 8 & $66.4 \%$ & 1 & 1 & 1 & 1 \\
\hline Public PaaS & High & Good & Low & Average & Average & Low & Good & $7 \mathrm{th}=$ & 8 & $66.4 \%$ & 1 & 1 & 1 & 1 \\
\hline Public SaaS & High & Good & Low & Average & Average & Low & Good & $7 \mathrm{th}=$ & 8 & $66.4 \%$ & 1 & 1 & 1 & 1 \\
\hline Public IaaS-Storage & High & Average & Low & Average & Average & Low & Good & 10th & 10 & $54.1 \%$ & 1 & 1 & 1 & 1 \\
\hline $\begin{array}{l}\text { Status quo } \\
\text { (not to adopt)- Legacy IT }\end{array}$ & Low & Weak & High & Average & Average & Low & Average & 11 th & 11 & $0 \%$ & 0 & 0 & 0 & 0 \\
\hline
\end{tabular}


The vertical (y) axis represents the total score achieved by the participants ranking of preference survey on the cloud services criteria. The bubble size and colour represent the alternatives.

Data can be presented in a different form, depends on its format and the required measurement. For example, the total scores for each alternative are calculated by the criteria weights and are plotted against 'solution cost' (Fig.6).

Figure 6 Example of value of money model

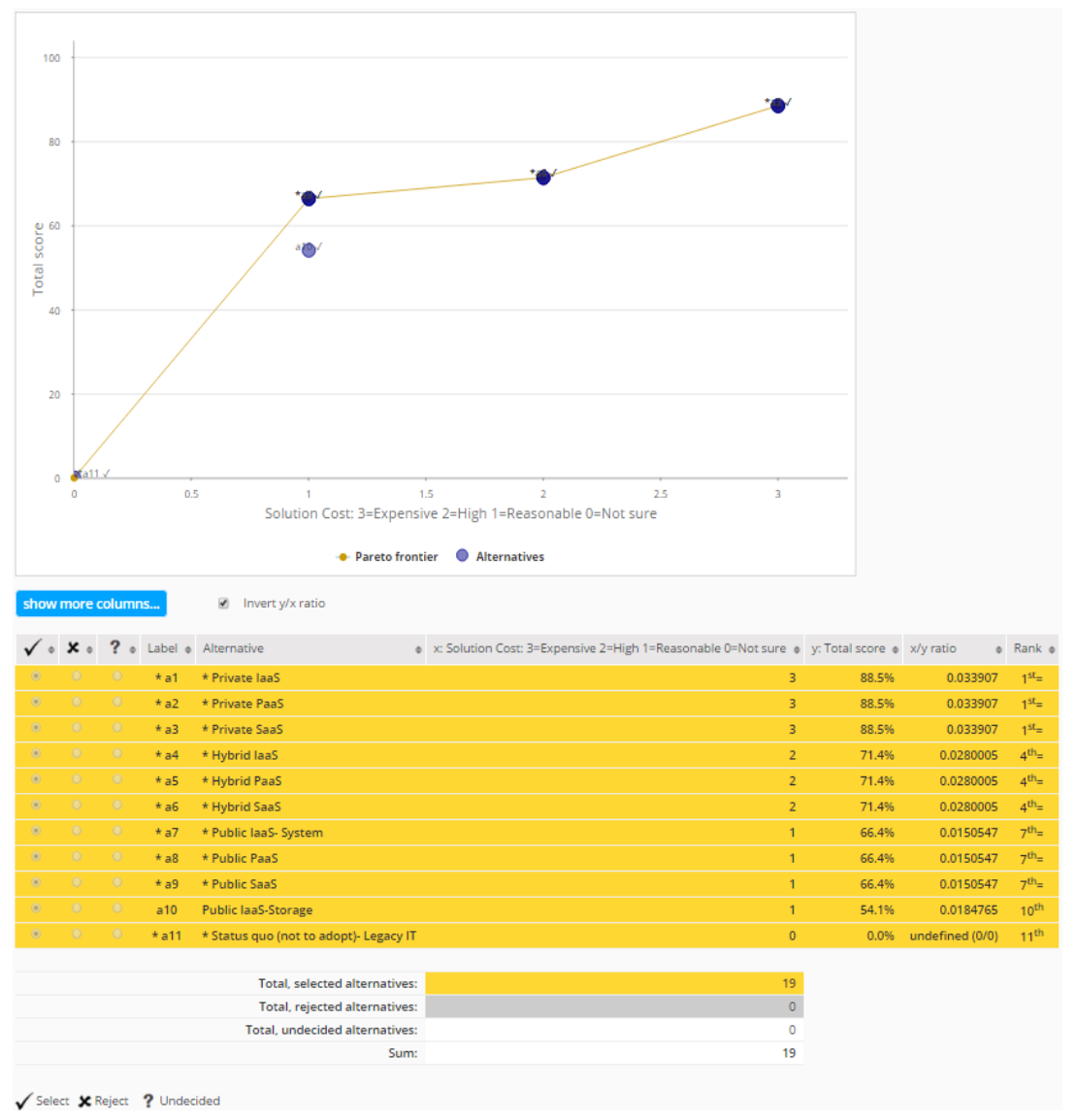

The 'value for money' tool can be extended to the decision model for a more efficient decision-making. This shall be considered in the expanding of the model with a cost-benefit analysis including more concrete market economic figures of cloud services for our future research. More precisely, cloud services costs and how organisations can budget for these services, and have a better understanding of what are they getting in comparison of the available solutions is paramount. This can be achieved by including a selection process with a budgeting option.

From the 5 cases, we examined and presented, the model was capable of producing solid results and proved to be feasible for the decision-making process. PAPRIKA method of pair-wise comparison and trade-off seems to have positive trust impact in user's intuitiveness towards the conducted activities, which therefore led to strong results. This is because PAPRIKA does not present the computation to the users whereas e.g. AHP users need to specify the preference intensity scale. An additional factor is that 
PAPRIKA's pair-wise process is fully viewed and transparent to the users, and it is recorded in the system and can be retrieved at any time. Moreover, the results were presented in various ways for better analysis and visualization.

\section{$6 \quad$ Future Research Opportunities}

The time devoted for conducting this study was sufficient to accomplish certain activities only. Convincing participants to take part in the conjoint analysis was not always an easy task due to their busy schedule and to our rigid time plan for this study. There is further potential in developing decision modelling by including the other activities that were not in the scope on this paper by further involving participants in additional activities in the distribution process and not only the preference survey that has been carried out and reported in this article. Participants can get involved more in other activities such as ranking survey - for them to rank concepts intuitively (participants can rank pre-specified concepts. Participants involvement can be linked with the additional data obtain by the researchers other relevant qualitative and quantities studies).

The main aim of the paper was to deliver a proof of concept that it is possible to model a decision-making process. Future research plans include modifying and refining the model to include more related factors to the context. Attributes such as regulatory support, awareness, and competence of cloud vendors have the potential to be the next candidates for further investigation. We also plan to conduct more activities to the decision model such as ranking survey and categorization survey and also increase the number of participants. In the current cases, we used SMEs decision makers as our judges. Further analysis could be conducted by using IT managers or other experts in ICT for cloud computing adoption assessment.

The Value for Money framework introduced in this paper can help decision makers in technological prioritising and selection. The process can be ensured with acceptable transparency measures and carried out systematically to all stakeholders who would be involved in the decision process. This process has not been yet applied in the real-world application of cloud computing prioritisation. Our future research aim is to pilot test the framework using real data (e.g. services pricing, speed, \& capacity) from cloud computing providers.

\section{Conclusion}

Decision making in the adoption of cloud computing is a multidimensional process. As a result, it is very useful to understand the entire scene behind the determinants that influence the decision towards the adoption of cloud models and services. Apparently, a simple, advance, and easy to use decision-making tool is useful for businesses to help them in making better judgments and therefore assist in increasing their productivity and further leveraging the country economically. This paper presented a new method and developed a cloud computing decision model based on real world cases based on five Australian SMEs. It was demonstrated how a new model based on Potentially All Pair-wise RanKings of all possible Alternatives (PAPRIKA) can be built, implemented, and applied to serve and solve the decision-making problems, taking the functionalities provided by PAPRIKA method based on the pair-wise comparison. The model illustrated how different alternatives of cloud computing services could be ranked. 
Essentially, it is up to decision-makers to select which services suits their needs and this made possible with the transparent model that take into account all relevant consideration. The model was distributed and tested using conjoint analysis with five SMEs decision makers.

Although the results can be considered quite detailed and comprehensive with various dimensions of visualization to offer a better framework for making a decision, there are additional opportunities for improvement of the model. For example, evaluation of cloud computing services providers can be included in the model 'alternatives'. In addition, more real-world preference analysis related to specific industry or targeted organisations can be conducted to assess the applicability and probably calibrate the model. Moreover, actual costing of services from various service providers can be considered to be extended to the model to provide decision makers with a better judgment with real market data. The dynamic change of cloud technology and the market condition regarding supply and demand of the cloud services requires continues re-evaluation of the concepts and the defined alternatives.

\section{Acknowledgments}

The authors thank 1000minds decision-making software (the software that supports PAPRIKA method) for providing us a free license and open access for the duration of the research, and Paul Hansen for his suggestions to our thinking in this area.

\section{References}

Abor, J. \& Quartey, P. 2010. Issues in SME development in Ghana and South Africa. International Research Journal of Finance and Economics, 39, 215-228.

ABS 2013. Business Use of Information Technology. Australian Bureau of Statistics. Canberra Australian Bureau of Statistics.

ACMA 2014. Communication Report Series: Report 2- Cloud Computing in Australia. Australian Government. Australia: The Australian Communications and Media Authority.

Al-Isma'ili, S., Li, M., He, Q. \& Shen, J. Cloud Computing Services Adoption in Australian SMEs: A Firm-level Investigation Proceedings of the 20th Pacific Asia Conference on Information Systems (PACIS 2016), 2016a. In press

Al-Isma'ili, S., Li, M., Shen, J. \& He, Q. Cloud Computing Adoption Determinants: An Analysis of Australian SMEs. Proceedings of the 20th Pacific Asia Conference on Information Systems (PACIS 2016), 2016b. In press.

Alismaili, S., Li, M. \& Shen, J. 2015a. Cloud Computing Adoption Decision Modelling for SMEs: From the PAPRIKA Perspective. Lecture Notes in Electrical Engineering. Springer Singapore.

Alismaili, S., Li, M., Shen, J. \& He, Q. A Multi-Perspective Approach for Understanding the Determinants of Cloud Computing Adoption among Australian SMEs. Australasian Conference on Information Systems, 2015b Adelaide, Australia paper ACIS/2015/99.

Amies, A., Sluiman, H., Tong, Q. G. \& Liu, G. N. 2012. Infrastructure as a Service Cloud Concepts. Developing and Hosting Applications on the Cloud.

Armbrust, M., Fox, A., Griffith, R., Joseph, A. D., Katz, R., Konwinski, A., Lee, G., Patterson, D., Rabkin, A. \& Stoica, I. 2010. A view of cloud computing. Communications of the ACM, 53, 50-58.

Bolloju, N. 2001. Aggregation of analytic hierarchy process models based on similarities in decision makers' preferences. European Journal of Operational Research, 128, 499-508. 
Boniface, M., Nasser, B., Papay, J., Phillips, S. C., Servin, A., Xiaoyu, Y., Zlatev, Z., Gogouvitis, S. V., Katsaros, G., Konstanteli, K., Kousiouris, G., Menychtas, A. \& Kyriazis, D. Platform-as-a-Service Architecture for Real-Time Quality of Service Management in Clouds. Internet and Web Applications and Services (ICIW), 2010 Fifth International Conference on, 9-15 May 2010 2010. 155-160.

Bridge, S. \& O'neill, K. 2012. Understanding enterprise: entrepreneurship and small business, Palgrave Macmillan.

Cameron, T. A. \& Deshazo, J. 2010. Differential attention to attributes in utilitytheoretic choice models. Journal of choice modelling, 3, 73-115.

Carcary, M., Doherty, E. \& Conway, G. 2014a. The Adoption of Cloud Computing by Irish SMEs-an Exploratory Study. Electronic Journal Information Systems Evaluation Volume, 17.

Carcary, M., Doherty, E., Conway, G. \& Mclaughlin, S. 2014b. Cloud Computing Adoption Readiness and Benefit Realization in Irish SMEs-An Exploratory Study. Information Systems Management, 31, 313-327.

Catteddu, D. \& Hogben, G. 2009. Cloud computing risk assessment. European Network and Information Security Agency (ENISA), 583-592.

Chang, V., Bacigalupo, D., Wills, G. \& Roure, D. D. 2010. A Categorisation of Cloud Computing Business Models. Proceedings of the 2010 10th IEEE/ACM International Conference on Cluster, Cloud and Grid Computing. IEEE Computer Society.

Chen, I. J. \& Popovich, K. 2003. Understanding customer relationship management (CRM): People, process and technology. Business process management journal, 9, 672-688.

Cloudandcompute.Com. 2014. Is The Private Cloud Really More Secure.

Cohn, T. \& Lindberg, R. A. 1972. How management is different in small companies, American Management Association New York.

Curran, J. \& Blackburn, R. 2000. Researching the small enterprise, Sage.

Dandridge, T. C. 1979. Children are not" little grown-ups": small business needs its own organizational theory. Journal of small business management, 17, 53-57.

Daniel, W., Chen, D., Liu, Q., Wang, F. \& Wei, Z. 2014. Emerging Issues in Cloud Storage Security: Encryption, Key Management, Data Redundancy, Trust Mechanism. Multidisciplinary Social Networks Research. Springer.

De Vaus, D. 2013. Surveys in social research, Routledge.

Dillon, S. \& Vossen, G. 2014. SaaS cloud computing in small and medium enterprises: A comparison between Germany and New Zealand. Working Papers, ERCIS-European Research Center for Information Systems.

Dutta, A., Peng, G. \& Choudhary, A. 2013. Risks in enterprise cloud computing: the perspective of IT experts. Journal of Computer Information Systems, 53, 39-48.

El-Gazzar, R. F. 2014. A Literature Review on Cloud Computing Adoption Issues in Enterprises. Creating Value for All Through IT. Springer.

Findthecompany. 2016. Companies and Organisations [Online]. Available: http://listings.ftb-companies-au.com/ [Accessed 23.01.2016].

Forman, E. H. \& Selly, M. A. 2001. Decision by objectives: how to convince others that you are right, World Scientific.

Godse, M. \& Mulik, S. An approach for selecting software-as-a-service (SaaS) product. Cloud Computing, 2009. CLOUD'09. IEEE International Conference on, 2009. IEEE, 155-158.

Gogrid. 2012. Cloud Computing Adoption Slower than Expected [Online]. Available: http://www.gogrid.com/news/2012/02/22/public-cloud-cloud-computingadoption-slower-expected [Accessed 03 April 2014].

Golan, O. \& Hansen, P. 2008. A new framework to help Israel's Health Basket Committee choose new health technologies. The VfM (Value for Money) Chart. Available: www.gertnerinst.org.il/health.

Hancock, I. \& Hutley, N. 2012. Modelling the Economic Impact of Cloud Computing. KPMG and Australian Information Industry Association (AIIA).

Hansen, P. \& Ombler, F. 2008. A new method for scoring additive multi-attribute value models using pairwise rankings of alternatives. Journal of Multi-Criteria Decision Analysis, 15, 87-107. 
Houghton, K. A. \& Winklhofer, H. 2004. The effect of website and e-commerce adoption on the relationship between SMEs and their export intermediaries. International Small Business Journal, 22, 369-388.

Hsu, P.-F., Ray, S. \& Li-Hsieh, Y.-Y. 2014. Examining cloud computing adoption intention, pricing mechanism, and deployment model. International Journal of Information Management, 34, 474-488.

Jain, L. \& Bhardwaj, S. 2010. Enterprise cloud computing: key considerations for adoption. International Journal of Engineering and Information Technology, 2, 113-117.

Jelonek, D. \& Wysłocka, E. 2014. Barriers to the development of cloud computing adoption and usage in SMEs in Poland.

Kim, W., Kim, S. D., Lee, E. \& Lee, S. Adoption issues for cloud computing. 2009 Kuala Lumpur. 2-5.

Koehler, P., Anandasivam, A., Dan, M. \& Weinhardt, C. Cloud Services from a Consumer Perspective. AMCIS, 2010. 329.

Lawrance, H. \& Silas, S. 2013. Efficient QoS Based Resource Scheduling Using PAPRIKA Method for Cloud Computing. International Journal of Engineering Science and Technology (IJEST), 5.

Li, A., Yang, X., Kandula, S. \& Zhang, M. CloudCmp: comparing public cloud providers. Proceedings of the 10th ACM SIGCOMM conference on Internet measurement, 2010. ACM, 1-14.

Mckinnar, E. \& Kathage, T. 2014. Cloud Computing Services in Australia. Research note, Austrade and the Department of Communications.

Mell, P. \& Grance, T. 2011. The NIST definition of cloud computing, recommendations of the National Institute of Standards and Technology, Special Publication 800-145[Online]. Available: http://csrc.nist.gov/publications/nistpubs/800-145/SP800-145.pdf. [Accessed 28/6/2014].

Michael, D., Kennedy, D., Wenstrup, J., Borno, R., Chen, J., Bezerra, J., Aggarwal, N. \& Rüßmann, M. 2013. Ahead Of The Curve: Lessons On Technology And Growth From Small-Business Leaders. Boston: The Boston Consulting Group. Disponible en: https://www. bcgperspectives. com/Images/Ahead_of_the_Curve_Oct_2013_tcm80-145844. pdf.

Minifie, J. 2014. The silver lining: cloud computing and small to medium enterprises. Sydney, Australia.

Misra, S. C. \& Mondal, A. 2011. Identification of a company's suitability for the adoption of cloud computing and modelling its corresponding Return on Investment. Mathematical and Computer Modelling, 53, 504-521.

Mohlameane, M. \& Ruxwana, N. 2014. The Awareness of Cloud Computing: A Case Study of South African SMEs. International Journal of Trade, Economics and Finance, 5, 6.

Moshkovich, H. M., Mechitov, A. I. \& Olson, D. L. 2002. Ordinal judgments in multiattribute decision analysis. European Journal of Operational Research, 137, 625-641.

Nist 2014. The NIST Definition of Cloud Computing. www.nist.gov.

Oecd, P. B. 2006. Financing SMEs and Entrepreneurs. OECD Observer, Paris.

Oliveira, T., Thomas, M. \& Espadanal, M. 2014. Assessing the determinants of cloud computing adoption: An analysis of the manufacturing and services sectors. Information \& Management, 51, 497-510.

Ombler, F. \& Hansen, P. 2012. 1000Minds software [Online]. http://www.1000minds.com.

Oracle. 2010. Oracle Cloud Computing [Online]. Redwood Shores, CA 94065, USA. Available: http://www.oracle.com/us/technologies/cloud/oracle-cloud-computingwp-076373.pdf [Accessed 23.06.2014.

Pike_Research 2010. Cloud Computing Energy Efficiency: Strategic and Tactical Assessment of Energy Savings and Carbon Emission Reduction Opportunities for Data Centers Utilizing SaaS, IaaS and PaaS.

Raghavarao, D., Wiley, J. B. \& Chitturi, P. 2010. Choice-based conjoint analysis: models and designs, CRC Press. 
Rehman, Z. U., Hussain, F. K. \& Hussain, O. K. Towards multi-criteria cloud service selection. Innovative Mobile and Internet Services in Ubiquitous Computing (IMIS), 2011 Fifth International Conference on, 2011. IEEE, 44-48.

Rio-Belver, R., Cilleruelo, E., Garechana, G., Gavilanes, J. \& Zabalza, J. 2012. New Management Models based in Cloud-Computing. Business and Management.

Ryan, M. \& Gerard, K. 2003. Using discrete choice experiments to value health care programmes: current practice and future research reflections. Applied health economics and health policy, 2, 55-64.

Saaty, T. L. 1990. How to make a decision: the analytic hierarchy process. European journal of operational research, 48, 9-26.

Saaty, T. L. 2008. Decision making with the analytic hierarchy process. International journal of services sciences, 1, 83-98.

Saini, I., Khanna, A. \& Kumar, V. 2012. ERP Systems: Problems and Solution with Special Reference to Small \& Medium Enterprises. International Journal of Research in IT \& Management, 2, 715-725.

Saripalli, P. \& Pingali, G. Madmac: Multiple attribute decision methodology for adoption of clouds. Cloud Computing (CLOUD), 2011 IEEE International Conference on, 2011. IEEE, 316-323.

Schneiderman, R. 2011. For Cloud Computing, the Sky Is the Limit [Special Reports]. Signal Processing Magazine, IEEE, 28, 15-144.

Storey, D. \& Cressy, R. 1996. Small business risk: A firm and bank perspective, Centre for Small and Medium Sized Enterprises, Warwick Business School.

Subashini, S. \& Kavitha, V. 2011. A survey on security issues in service delivery models of cloud computing. Journal of Network and Computer Applications, 34, $1-11$.

Sullivan, T. 2012. Using MCDA (Multi-Criteria Decision Analysis) to prioritise publicly-funded health care. University of Otago.

Tsai, W.-T., Shao, Q., Huang, Y. \& Bai, X. Towards a scalable and robust multitenancy SaaS. Proceedings of the Second Asia-Pacific Symposium on Internetware, 2010. ACM, 8.

Welsh, J. A. \& White, J. F. 1981. A small business is not a little big business. Harvard business review, 59, 18-\&.

Wu, W.-W., Lan, L. W. \& Lee, Y.-T. 2013. Factors hindering acceptance of using cloud services in university: a case study. The Electronic Library, 31, 84-98.

Yang, H. \& Tate, M. 2012. A descriptive literature review and classification of cloud computing research. Communications of the Association for Information Systems, 31, 35-60.

Yeboah-Boateng, E. O. \& Essandoh, K. A. 2014. Factors Influencing the Adoption of Cloud Computing by Small and Medium Enterprises (SMEs) in Developing Economies. International Journal of Emerging Science and Engineering (IJESE), 2, 13-20. 
Appendix A: Comparison of scoring methods

\begin{tabular}{|c|c|c|c|c|c|c|}
\hline & $\begin{array}{l}\text { SWING/ } \\
\text { SMART }\end{array}$ & $\mathrm{DCE} / \mathrm{CA}$ & $\mathrm{ACA}$ & AHP & PAPRIKA & Outranking \\
\hline $\begin{array}{l}\text { Elicitation } \\
\text { method }\end{array}$ & $\begin{array}{l}\text { Allocate } \\
\text { points } \\
\text { from least } \\
\text { preferred } \\
\text { to most } \\
\text { preferred; } \\
\\
\text { Consider } \\
\text { all criteria } \\
\text { at same } \\
\text { time }\end{array}$ & $\begin{array}{l}\text { Choice } \\
\text { based; } \\
\text { Usually } \\
4+ \\
\text { criteria in } \\
\text { each } \\
\text { scenario; } \\
\text { two or } \\
\text { more } \\
\text { scenarios }\end{array}$ & $\begin{array}{l}\text { Choice } \\
\text { based; } \\
\text { Self- } \\
\text { explication; } \\
\text { Computer- } \\
\text { based } \\
\text { interview }\end{array}$ & $\begin{array}{l}\text { Pairwise } \\
\text { comparisons; } \\
\text { Ratio } \\
\text { judgements } \\
\text { on a nine- } \\
\text { point scale }\end{array}$ & $\begin{array}{l}\text { Pairwise } \\
\text { comparisons/ } \\
\text { choice based }\end{array}$ & $\begin{array}{l}\text { Assign } \\
\text { weights; } \\
\text { Pairwise } \\
\text { comparisons } \\
\text { based on "at } \\
\text { least as good } \\
\text { as" }\end{array}$ \\
\hline $\begin{array}{l}\text { Number of } \\
\text { judgements } \\
\text { required }\end{array}$ & $\begin{array}{l}\text { Minimum } \\
\text { number of } \\
\text { judgements }\end{array}$ & $\begin{array}{l}\text { Often } \\
\text { limited } \\
\text { number } \\
\text { of choice } \\
\text { sets to } \\
\text { reduce } \\
\text { overload }\end{array}$ & $\begin{array}{l}\text { Usual time } \\
\text { is } \\
45 \text { mins, } \\
\text { depending } \\
\text { on number } \\
\text { of choice } \\
\text { sets }\end{array}$ & $\begin{array}{l}\text { Depends on } \\
\text { number of } \\
\text { attributes }\end{array}$ & $\begin{array}{l}\text { Depends on } \\
\text { number of } \\
\text { criteria/ levels } \\
\text { but likely to } \\
\text { be more than } \\
\text { DCE/CA/AHP }\end{array}$ & $\begin{array}{l}\text { Depends on } \\
\text { number of } \\
\text { criteria }\end{array}$ \\
\hline Points/ & Direct & Indirect & Indirect & Indirect & Indirect & Direct/indirect \\
\hline activen & $\begin{array}{l}\text { Assign } \\
\text { weights }\end{array}$ & $\mid \begin{array}{l}\text { Statistical } \\
\text { analysis }\end{array}$ & $\begin{array}{l}\text { Statistical } \\
\text { analysis }\end{array}$ & $\begin{array}{l}\text { Mathematical } \\
\text { algorithm }\end{array}$ & $\begin{array}{l}\text { Mathematical } \\
\text { algorithm }\end{array}$ & $\begin{array}{l}\text { Assign } \\
\text { weights and } \\
\text { thresholds }\end{array}$ \\
\hline $\begin{array}{l}\text { Online } \\
\text { individual } \\
\text { surveys }\end{array}$ & No & Yes & No & Yes & Yes & Yes \\
\hline $\begin{array}{l}\text { Individual } \\
\text { weights }\end{array}$ & Yes & No & No & Yes & Yes & No \\
\hline $\begin{array}{l}\text { Validity/ } \\
\text { reliability }\end{array}$ & $\begin{array}{l}\text { Arbitrarily } \\
\text { assign } \\
\text { points }\end{array}$ & $\begin{array}{l}\text { Limited } \\
\text { number } \\
\text { of choice } \\
\text { sets } \\
\text { presented }\end{array}$ & $\begin{array}{l}\text { Self- } \\
\text { explication; } \\
\\
\text { Decision- } \\
\text { makers } \\
\text { have } \\
\text { different } \\
\text { choice sets }\end{array}$ & $\begin{array}{l}\text { No attribute } \\
\text {;levels (e.g. } \\
\text { small, } \\
\text { medium, } \\
\text { large) } \\
\text { Consistency } \\
\text { ratio }\end{array}$ & $\begin{array}{l}\text { Less decision- } \\
\text { maker burden } \\
\text { Check for } \\
\text { consistency }\end{array}$ & $\begin{array}{l}\text { No levels; } \\
\text { Arbitrarily } \\
\text { assigned } \\
\text { weights and } \\
\text { thresholds }\end{array}$ \\
\hline
\end{tabular}

Source: Adopted from (Sullivan, 2012) 